Special issue in honor of Prof. H.K. Lichtenthaler

\title{
REVIEW
}

\section{Chlorophyll fluorescence imaging for process optimisation in horticulture and fresh food production}

\author{
W.B. HERPPICH \\ Department of Horticultural Engineering, Leibniz-Institute for Agricultural Engineering and Bioeconomy, \\ Max-Eyth-Allee 100, 14469 Potsdam, Germany
}

\begin{abstract}
Chlorophyll $a$ fluorescence analysis (CFA) has been accepted to study postharvest activity and stability of photosynthesis of vegetables and salad greens, and some fruits. Commercial chlorophyll fluorescence imaging (CFI) systems may provide additional insight into spatial and temporal dynamics of photosynthesis. This yields valuable information on the effects of postharvest handling and processing (sorting, cutting, packaging, etc.) on physiological activity and 'internal quality' of green produce, and its changes. Here, meaning and physiological basics of relevant fluorescence parameters is briefly summarised, while major focus is on recent applications of CFI to evaluate quality and quality maintenance during postharvest handling and minimal processing of fresh fruits and vegetables. CFI is given surprisingly little attention in the monitoring of postharvest quality, although it is suitable for adjusting and/or optimising innovative postharvest techniques. Knowledge of the physiological base and the limit of interpretation is indispensable for meaningful interpretations of results to draw correct consequences.
\end{abstract}

Keywords: internal quality; photosystem II; plant physiology; postharvest research; postharvest processing.

\section{Highlights}

- CFI is given surprisingly little attention in the monitoring of postharvest

- CFI may help optimising quality maintenance in postharvest handling and processing

- Knowledge of physiological base is indispensable to draw correct consequences
Received 16 February 2021

Accepted 16 June 2021

Published online 19 July 2021

phone: 49-3315699620

e-mail: wherppich@atb-potsdam.de

Abbreviations: CAP - cold atmospheric plasma; Car - carotenoids; CFA - chlorophyll a fluorescence analysis; CFI - chlorophyll fluorescence imaging; Chl - chlorophyll; CI - chilling injuries; D - relative dissipation of absorbed energy as heat; E - relative dissipation of absorbed energy as unexplained excess; ETR - electron transport rate; $\mathrm{F}_{0}$ - minimal fluorescence yield of the darkadapted state; $\mathrm{F}_{0}{ }^{\prime}$ - minimal fluorescence yield of the light-adapted state; $\mathrm{F}_{\mathrm{m}}$ - maximal fluorescence yield of the dark-adapted state; $\mathrm{F}_{\mathrm{m}}{ }^{\prime}$ - maximal fluorescence yield of the light-adapted state; $\mathrm{F}_{\mathrm{p}}$ - peak fluorescence signal; $\mathrm{F}_{\mathrm{t}}$ - terminal steady-state fluorescence; $\mathrm{F}_{\mathrm{v}}-$ variable fluorescence; $F_{v} / F_{m}$ - potential maximal quantum yield of PSII; HHP - high hydrostatic pressure; HWT - hot water treatment; $\mathrm{I}_{\mathrm{abs}}$ - number of absorbed photons; MAP - modified atmosphere packaging; MRI - magnetic resonance imaging; NIR - near-infrared; NMR - nuclear magnetic resonance, NPQ - nonphotochemical quenching; $\mathrm{P}$ - relative dissipation of absorbed energy as photochemistry; PPFR - photosynthetic active photon flux rate; $\mathrm{q}_{\mathrm{L}}$ - lake model-based photochemical quenching coefficient; $\mathrm{q}_{\mathrm{N}}$ - nonphotochemical quenching coefficient; $\mathrm{q}_{\mathrm{P}}$ - photochemical quenching coefficient; SDBD - surface dielectric barrier discharge; sHTW - short-term hotwater treatments; $\mathrm{T}_{\text {crit }}$ - critical temperature; UV/VIS - ultraviolet-visible; $\mathrm{Y}_{\mathrm{II}}$ - quantum yields of photochemical energy conversion; $\mathrm{Y}_{\mathrm{NO}}-$ nonregulated nonphotochemical energy loss in PSII; $\mathrm{Y}_{\mathrm{NPQ}}-$ regulated nonphotochemical energy loss in PSII; $\Delta \mathrm{F} / \mathrm{F}_{\mathrm{m}}{ }^{\prime}=\mathrm{Y}=\phi_{\mathrm{PSII}}=$ $\left(\mathrm{F}_{\mathrm{m}}{ }^{\prime}-\mathrm{F}_{\mathrm{t}}\right) / \mathrm{F}_{\mathrm{m}}{ }^{\prime}-$ actual quantum yield of PSII.

Acknowledgements: The author thanks Matthias Baier, Elke Bauriegel, Graziele Grossi Bovi, Hanna Brabandt, Sara Bußler, Oluwafemi Caleb, Julia Foerster, Manfred Forstreuter, Antje Fröhling, Martin Geyer, Antje Giebel, Ute Gräber, Karin Hassenberg, Susanne Huyskens-Keil, Tina Kabelitz, Andrzej Kurenda, Manfred Linke, Pramod Mahajan, Guido Rux, Oliver Schlüter, Artur Zdunek, Manuela Zude, and Tamás Zsom for their great collaboration to yield all that data and to write our 'few' papers, dealing with the application of CFI in pre- and postharvest horticultural research and Craig E. Martin for checking the English.

Conflict of interest: The author declares no conflict of interest. 


\section{Introduction}

Efficient, rapid, objective and nondestructive monitoring of the quality and the safety status of horticultural produce is indispensable during production, storage, and postharvest handling of fresh produce (Abbott 1999, Butz et al. 2005, Zhang et al. 2014), especially of fresh, minimally processed convenience food (Rico et al. 2007, Hägele et al. 2016, Erkan and Yildirim 2017). In this context, a great variety of newly developed and well-established techniques are meanwhile available and in practical use. Among these, particularly those related to the imagingbased evaluation of optical produce properties have been rapidly advanced during recent years. This includes conventional RGB (red, green, blue) image analysis, but also UV/VIS (ultraviolet-visible)-, NIR (near-infrared)-, hyperspectral-, and fluorescence spectroscopy, X-ray- and NMR (nuclear magnetic resonance)-tomography (MRI; magnetic resonance imaging), biospeckle and chlorophyll $a$ fluorescence imaging (Abbott 1999, Nicolaï et al. 2007, Herppich et al. 2012, Zdunek and Herppich 2012, DonisGonzález et al. 2014, Abasi et al. 2018). In terms of quality and safety, the analytical approach of each of these techniques bases on the evaluation of the actual metabolic activity of the investigated product. This follows the basic premise that a high physiological capability of the fresh product under investigation also reflects high 'internal' quality (Geyer et al. 1999, Butz et al. 2005). This is valid in both fruit and vegetable production (Baker and Rosenqvist 2004, Gorbe and Calatayud 2012), but is particularly relevant in postharvest horticultural research on fruits and vegetables (DeEll et al. 1999, Rico et al. 2007, Hägele et al. 2016, Erkan and Y1ldırım 2017).

In postharvest research on fruits and vegetables, scientific focus is mostly placed on the analysis of respiration (loss of stored carbohydrates; Kader 1987, Caleb et al. 2016) and transpiration (loss of stored water) as indicators of the variation of physiological competence (Geyer et al. 1999, Bovi et al. 2018). In chlorophyllcontaining produce, such as unripe or green-ripe fruit (e.g., tomato, apples, pears, etc.) or greens (lettuce, spinach, broccoli, etc.), photosynthesis remains active after harvest. Monitoring the photosynthetic activity and its potential variation thus provides a helpful means to sensitively quantify 'produce quality'. On the other hand, the entire metabolic pathway is extremely susceptible to various internal (maturation, aging, senescence, etc.) and external (salinity, drought, heat, cold, frost, etc.) stimuli and their changes. Consequently, analyses of photosynthetic performance facilitate the comprehensive evaluation of biotic and abiotic stress effects (Lichtenthaler et al. 1983, von Willert et al. 1995, Nedbal et al. 2000a, Schlüter et al. 2009, Bauriegel et al. 2010, Bauriegel and Herppich 2014; Baier et al. 2015, Dong et al. 2019) both during production (Baker and Rosenqvist 2004, Brabandt et al. 2014, Bußler et al. 2015, Sandmann et al. 2018) and postharvest handling and processing of fruit and vegetables (Schlüter et al. 2009, Baier et al. 2013, 2014, 2015; Kurenda et al. 2014, Herppich et al. 2020).
Besides the common determination of $\mathrm{CO}_{2}$ and $\mathrm{O}_{2}$ gas exchange (Matyssek and Herppich 2020), chlorophyll $a$ fluorescence analysis (CFA) has meanwhile been widely accepted as an elegant, rapid, noninvasive, and comprehensive method to remotely monitor photosynthetic activity (Lichtenthaler 1988, Maxwell and Johnson 2000, Baker et al. 2007, Porcar-Castell et al. 2014, Matyssek and Herppich 2020). In addition, CFA has been frequently used in horticultural research to study postharvest activity of vegetables and salad greens, and some fruit (DeEll et al. 1999, Herppich and Zude 2002, Herppich 2003, DeEll and Toivonen 2012, Gorbe and Calatayud 2012, Hägele et al. 2016, Lu and Lu 2020). In this context, recent commercially available chlorophyll $a$ fluorescence image (CFI) systems are advantageous over spot measurements with other fluorometers (Matyssek and Herppich 2020), potentially revealing both spatial and temporal dynamics of photosynthesis (Nedbal et al. 2000b, Schlüter et al. 2009, Herppich et al. 2012, Sánchez-Moreiras et al. 2020). If no spatial variations are expected or relevant, these images present the means of the respective fluorescence parameters over the entire produce (Schlüter et al. 2009, Herppich et al. 2012, Matyssek and Herppich 2020).

Thus, it is not surprising that CFI is being increasingly applied for process optimisation in horticulture and in fresh food production. According to a recent literature search in the Web of Science (ISI, Clarivate Analytics), using the title keywords, chlorophyll fluorescence and imaging, 52 articles and reviews could be found for the last five years (2016-2020). Five of the articles dealt with topics related to postharvest handling of fruit, vegetables or ornamentals. The half-decade before, there was only one such paper out of 37 papers. Although the use of this technique seems to be relatively limited in postharvest research compared to other horticultural or agricultural fields (e.g., plant production, breeding, disease detection), application of CFI nevertheless now covers a number of interesting topics in postharvest handling and minimal processing of fresh fruits and vegetables.

\section{Processing in fresh horticultural convenience food production}

Except for some climacteric fruit, the quality of most produce can only decline after harvest. Thus, postharvest handling of fresh horticultural food mainly aims to control and reduce deterioration. This includes careful, gentle, and safe transporting, cooling, cleaning, sorting, and packing of fruit and vegetables, preventing mechanical damage and reducing physiological activity and mass losses. It also covers various means to directly reduce or at least prevent the growth of decay-related pathogens. At all steps of the diverse postharvest handling chains, automation became indispensable in recent years, to reduce workload and production costs. This is even more important for the production of minimally processed convenient ready-toeat fresh food, such as fresh-cut salads and fruit salads. Many new techniques and methods have been developed or adapted at all the above steps. All these technologies 
needed to be carefully evaluated before they could be introduced in practice. They must be effective in reaching the basic purposes but need to be gentle enough not to negatively impact the perishable fresh produce.

Various steps of the entire complex physiological process of photosynthesis are major initial target of many stresses, making it a suitable and sensitive marker for evaluating the efficacy and, especially, the harmlessness of the processing approaches. In particular, rapid noninvasive CFI is of great value in this context, at least for green chlorophyll-containing fruit and vegetables. For the comprehensive characterisation of the stability and efficiency of the photosynthetic apparatus, and the degree of activation, protection and/or damage, many different fluorescence parameters are available (Maxwell and Johnson 2000, Baker et al. 2007, Matyssek and Herppich 2020). In this paper, a short recapitulation of chlorophyll fluorescence basics and chlorophyll fluorescence parameters will be then followed by a focus on recent applications of CFI in various fields of respective fresh food processing, which will be introduced and discussed in detail.

\section{Chlorophyll fluorescence imaging}

The basics: In chloroplasts of green plant tissues, chlorophyll $a$ molecules are incorporated at fixed positions in specialized protein complexes, the photosystems (PSI and PSII), and in several antenna and light-harvesting complexes (LHC). Only outer antenna complexes and LHC also contain chlorophyll $b$. Chlorophylls are the most important light-harvesting pigments, absorbing photons particularly in the wavelength range of $400-480 \mathrm{~nm}$ (blue) and $630-700 \mathrm{~nm}$ (red). They are accompanied by smaller amounts of carotenoids, functioning in photosynthetic energy absorption, as structural or as photoprotective molecules. The photosystems, along with other protein complexes are located within the thylakoids, the inner chloroplastic membrane network. PSII and PSI, some other proteins and electron transport metabolites form the photosynthetic electron transport chain, which primarily converts the absorbed light into metabolically usable energy (ATP) and reduction equivalents $\left(\mathrm{NADPH} / \mathrm{H}^{+}\right)$. These equivalents are predominantly used in the biochemical reactions of photosynthesis for the assimilation of $\mathrm{CO}_{2}$ into sugars.

On the other hand, at room temperature, chlorophyll $a$ molecules of mainly but not exclusively PSII (Pfündel 1998, Henriques 2009) may also radiatively emit part of the absorbed energy as red fluorescence photons of somewhat longer wavelength (mainly between approx. 660 and $760 \mathrm{~nm}$ ) and, hence, lower energy, in photosynthetically active plants. Overall fluorescence can make up 30 to $50 \%$ of the total absorbed light energy. However, due to effective reabsorption by other chlorophyll molecules, net fluorescence is only 2 to $3 \%$ under normal conditions (Krause and Weis 1991, Agati et al. 1993, Buschmann 2007). Furthermore, only the energy equivalent to red wavelengths band is used photochemically. In contrast, the energy of 'blue' photons in excess of the 'red portion' is dissipated as heat by chlorophyll molecules. In concerted action with some xanthophylls, the energy absorbed in excess to what can be used photochemically may be safely dissipated as heat as part of complex photosynthetic protection mechanisms.

If in a stress situation (e.g., heat, cold, frost, drought, anoxia, salinity, light, etc.) light energy supply exceeds its demand in biochemistry, the above-mentioned series of protective mechanisms are further activated and energy flow into heat and, to a smaller extent, into fluorescence increases. Because fluorescence light is relatively simple to measure, it may be used as an indicator of many disturbances in photosynthesis.

Modern pulse amplitude-modulated (PAM) fluorometers do not only record the continuous steady-state fluorescence. Based on theso-called Kautskyeffect(Kautsky and Hirsch 1931) and in combination with the saturationpulse technique (Schreiber et al. 1986), information on the maximum and the actual activity, and the integrity of PSII as well as on the relative contribution of photochemical and thermal (nonphotochemical) energy dissipation can be obtained. For a comprehensive analysis, green tissues must be dark-adapted for a certain time to completely deactivate nonphotochemical energy dissipation and photochemical reactions of $\mathrm{CO}_{2}$ assimilation. The latter guarantees the full oxidation of the plastoquinone (PQ) pool. Illumination with short, photosynthetically inactive light pulses [approx. $2 \mu \operatorname{mol}\left(\right.$ photon) $\mathrm{m}^{-2} \mathrm{~s}^{-1}$ ] induces the initial fluorescence $\left(\mathrm{F}_{0}\right)$ arising from chlorophyll $a$ molecules of PSII antenna complexes (Krause and Weis 1991, Matyssek and Herppich 2020). Then, a short (mostly $<1 \mathrm{~s})$ saturating light pulse rapidly excites all chlorophyll molecules and, thus, elicits a maximum fluorescence signal $\left(F_{m}\right)$. Because any photochemical or nonphotochemical energy dissipation is prevented, fluorescence is the only pathway of de-excitation (Fig. 1).

If the object is afterwards irradiated with a continuous actinic, photosynthesis-driving light, the fluorescence signal changes in a characteristic pattern, the so-called Kautsky curve (Krause and Weis 1991, von Willert et al. 1995, Matyssek and Herppich 2018). The rise from $F_{0}$ to the peak fluorescence $\left(F_{p}\right)$ reflects a complex series of reactions including primary charge separation and electron flow in PSII and in the entire photosynthetic electron chain. The decline of the fluorescence signal from $F_{p}$ to the terminal steady-state fluorescence $\left(F_{t}\right)$ is partially governed by the initial induction and the final fine tuning of all photochemical processes, e.g., the assimilation of $\mathrm{CO}_{2}$. Furthermore, the activation of the nonphotochemical mechanisms further leads to the quenching of fluorescence. If, in the steady state with fully functional photosynthesis, a saturation pulse is given, an intermittent maximum fluorescence $\left(\mathrm{F}_{\mathrm{m}}{ }^{\prime}\right)$ signal will be recorded. This $\mathrm{F}_{\mathrm{m}}{ }^{\prime}$ is smaller than $\mathrm{F}_{\mathrm{m}}$ because of the consisting nonphotochemical energy dissipation. On the other hand, the fluorescence rise from $F_{t}$ to $F_{m}$ ' indicates the part of potential fluorescence that is currently quenched by photochemistry. Finally, the fluorescence measured directly after switching off the 


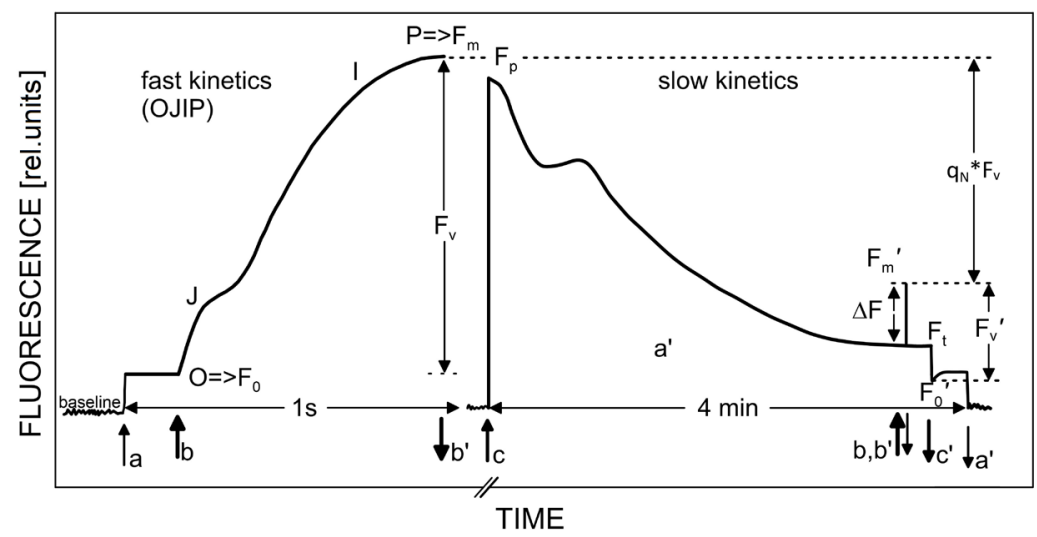

Fig. 1. Example of a typical chlorophyll $a$ fluorescence transient as recorded on a dark-adapted (15 min) leaf of Delosperma tradescantioides with a PAM fluorometer [modified after von Willert et al. (1995)] after switching on the measuring light (a). The fast fluorescence kinetics (left side), induced by a short (1 s) saturating light pulse [b; PFR $\left.>2,500 \mu \mathrm{mol}(\mathrm{photon}) \mathrm{m}^{-2} \mathrm{~s}^{-1}\right]$ after recording the dark fluorescence signal $\left(\mathrm{F}_{0}=\mathrm{O}\right)$ also illustrates the cardinal points $(\mathrm{O}, \mathrm{J}, \mathrm{I}, \mathrm{P})$ used in the OJIP-test. Here, the maximal fluorescence signal $\left(\mathrm{F}_{\mathrm{m}}\right)$ is identical to P. After 5 min of dark relaxation (not explicitly shown), the slow kinetics was induced by actinic light (c) of approx. $650 \mu \mathrm{mol}$ (photon) $\mathrm{m}^{-2} \mathrm{~s}^{-1}$. When the terminal fluorescence signal $\left(\mathrm{F}_{\mathrm{t}}\right)$ was reached, a further saturation light pulse was given and the maximal fluorescence of the illuminated leaf $\left(\mathrm{F}_{\mathrm{m}}{ }^{\prime}\right)$ measured. Then, the actinic light was switched off again and the dark fluorescence signal $\left(\mathrm{F}_{0}{ }^{\prime}\right)$ of the previous illuminated leaf recorded. From the above parameters, the respective variable fluorescence values, $\mathrm{F}_{\mathrm{v}}=\mathrm{F}_{\mathrm{m}}-\mathrm{F}_{0}, \mathrm{~F}_{\mathrm{v}}{ }^{\prime}=\mathrm{F}_{\mathrm{m}}{ }^{\prime}-\mathrm{F}_{0}{ }^{\prime}$, and $\Delta \mathrm{F}=\mathrm{F}_{\mathrm{m}}{ }^{\prime}-\mathrm{F}_{\mathrm{t}}$, could be calculated. In the slow kinetics, the contribution of nonphotochemical quenching on the reduction of $F_{m}$ to $F_{m}{ }^{\prime}$ is also indicated.

actinic irradiation or after rapidly darkening the object yields $\left(\mathrm{F}_{0}{ }^{\prime}\right)$, reflecting the dark fluorescence emitted from antenna chlorophylls in the 'light-adapted' state (Fig. 1).

Despite different approaches available to measure and to analyse chlorophyll fluorescence data [e.g., multicolour fluorescence (Lichtenthaler 2021) or the 'OJIP-test' of the rapid polyphasic $F_{0}$ to $F_{m}$ rise as measured with simple 'continuous light' fluorometers (Strasser et al. 1995, Lazár 2006, Matyssek and Herppich 2018)], mainly the 'conventional' fluorescence analysis using the pulseamplitude modulated 'PAM-fluorometry' (Schreiber et al. 1986) will be dealt with in the following for the sake of simplicity and due to its high flexibility.

Chlorophyll fluorescence parameters and their meaning: From the above fluorescence signals, a still increasing number of other useful parameters have been proposed and can be derived by simple calculations. Very easy to measure is the ratio of the variable fluorescence $F_{v}$ $\left(F_{v}=F_{m}-F_{0}\right)$ and $F_{m}$ of dark-adapted samples. $F_{v} / F_{m}$ is an indicator of the potential maximum photochemical quantum efficiency of PSII and is thus a valuable tool to determine both capacity and stability of photosynthesis (Krause and Weis 1991, von Willert et al. 1995, Matyssek and Herppich 2018) and its direct response to internal and external constraints.

When a saturation pulse is applied to irradiated samples, the measured fluorescence signals, $\mathrm{F}_{\mathrm{t}}$ and $\mathrm{F}_{\mathrm{m}}$ ', can be used to estimate the fraction of the maximum photochemical quantum efficiency of PSII that is still operating. This actual photochemical quantum efficiency, calculated as $\left(F_{m}{ }^{\prime}-F_{t}\right) / F_{m}{ }^{\prime}$, is often termed $\Delta F / F_{m}{ }^{\prime}$, but also a wealth of other designations can be found $\left(\mathrm{Y}, \phi_{\mathrm{PSII}}, \mathrm{F}_{\mathrm{q}}{ }^{\prime} / \mathrm{F}_{\mathrm{m}}{ }^{\prime} \ldots\right)$. It has been shown that, as the ratio of used to absorbed energy, $\Delta \mathrm{F} / \mathrm{F}_{\mathrm{m}}$ ' is directly proportional to the linear electron flow through PSII. Hence, it can be used to estimate the electron transport rate (ETR) by multiplying it with the number of absorbed photons, $\mathrm{I}_{\mathrm{abs}}$ (the product of the rate of incident photons, PPFR) and the absorption coefficient, $\alpha$, and the relative distribution of photons between PSII and PSI as $\mathrm{ETR}=\Delta \mathrm{F} / \mathrm{F}_{\mathrm{m}}{ }^{\prime} \times \mathrm{I}_{\mathrm{abs}} \times 0.5$. Here, the (over)simplifications are generally accepted that the absorption coefficient is 0.84 (often correct, e.g., for many herbs) and that the photon distribution between PSII and PSI is equal. Under some precautions, ETR is a valuable indicator of gross photosynthesis.

The comparison of the variable fluorescence measured on irradiated and on dark-adapted samples reflects the activity of nonphotochemical mechanisms, i.e., the reason for the reduction of $F_{m}$ to $F_{m}$ '. Accordingly, the nonphotochemical quenching coefficient $\left(\mathrm{q}_{\mathrm{N}}\right.$; Schreiber et al. $1986)$ is defined as $\mathrm{q}_{\mathrm{N}}=1-\mathrm{F}_{\mathrm{v}}{ }^{\prime} / \mathrm{F}_{\mathrm{v}}=1-\left(\mathrm{F}_{\mathrm{m}}{ }^{\prime}-\mathrm{F}_{0}{ }^{\prime}\right) /\left(\mathrm{F}_{\mathrm{m}}-\mathrm{F}_{0}\right)$. Likewise, the activity of photochemical quenching may be estimated from the rise of the fluorescence signal from $F_{t}$ to $F_{m}$ ', which reflects the transient closure of all (still open) PSII reaction centres, i.e., the transient inhibition of photochemistry. Hence, the photochemical quenching coefficient $\left(\mathrm{q}_{\mathrm{P}}\right)$ is defined as $\mathrm{q}_{\mathrm{P}}=\Delta \mathrm{F} / \mathrm{F}_{\mathrm{v}}=$ $\left(F_{m}{ }^{\prime}-F_{t}\right) /\left(F_{m}-F_{0}\right)$. Very similar, the lake model-based $\mathrm{q}_{\mathrm{L}}\left[=\left(\mathrm{F}_{\mathrm{m}}{ }^{\prime}-\mathrm{F}_{\mathrm{t}}\right) \times \mathrm{F}_{0}{ }^{\prime} /\left(\mathrm{F}_{\mathrm{m}}{ }^{\prime}-\mathrm{F}_{0}{ }^{\prime}\right) \times \mathrm{F}_{\mathrm{t}}\right]$ indicates the fraction of open PSII centres (Klughammer and Schreiber 2008). In a different approach, based on the Stern-Volmer equation, nonphotochemical quenching (NPQ) is calculated as NPQ $=\left(\mathrm{F}_{\mathrm{m}}-\mathrm{F}_{\mathrm{m}}{ }^{\prime}\right) / \mathrm{F}_{\mathrm{m}}{ }^{\prime}$ (cf. Klughammer and Schreiber 2008). NPQ is directly related to the total amount of quenchers involved in the nonphotochemical 
protection mechanisms, while $\mathrm{q}_{\mathrm{N}}$ closely reflects their actual functioning.

Besides many other more or less meaningful fluorescence parameters, calculation of complementary PSII quantum yields has become very popular in recent years (Klughammer and Schreiber 2008). Similar to the terms for dissipation of absorbed energy as heat $\left[\mathrm{D}=1-\left(\mathrm{F}_{\mathrm{m}}{ }^{\prime}-\mathrm{F}_{0}{ }^{\prime}\right)\right.$ / $\left.\mathrm{F}_{\mathrm{m}}{ }^{\prime}\right]$, photochemistry $\left(\mathrm{P}=\Delta \mathrm{F} / \mathrm{F}_{\mathrm{v}}\right)$, and the unexplained excess $(\mathrm{E}=1-\mathrm{D}-\mathrm{P})$ proposed by Demmig-Adams et al. (1996), more recently quantum yields of photochemical energy conversion $\left(\mathrm{Y}_{\mathrm{II}}=\Delta \mathrm{F} / \mathrm{F}_{\mathrm{v}}\right)$ and regulated $\left(\mathrm{Y}_{\mathrm{NPQ}}=\mathrm{F}_{\mathrm{t}} / \mathrm{F}_{\mathrm{m}}{ }^{\prime}-\mathrm{F}_{\mathrm{t}} / \mathrm{F}_{\mathrm{m}}\right)$ and nonregulated nonphotochemical energy loss in PSII $\left(\mathrm{Y}_{\mathrm{NO}}=\mathrm{F} / \mathrm{F}_{\mathrm{m}}\right)$ were developed (Klughammer and Schreiber 2008). Here, F denotes fluorescence signals obtained immediately before the saturation pulse. The latter approach may simplify the measurements because it does not include the assessment of $\mathrm{F}_{0}$ and, most important, $\mathrm{F}_{0}{ }^{\prime}$. Of course, it still demands the determination of $F_{m}$, which can be complicated in the field and under conditions of long-term stress effects, e.g., due to long-lasting NPQ components (Herppich 2000).

Evaluation of CF images: Certainly, the major advantages of the application of modulated light chlorophyll fluorescence imaging for the evaluation of pre- and postharvest performance of crops are clear and convincing (Nedbal et al. 2000a,b,c; Oxborough 2004, Herppich et al. 2012, Dong et al. 2019, Sánchez-Moreiras et al. 2020). Current CFI systems enable users to obtain dynamic highresolution images in daylight or darkness even under field conditions, therefore, largely facilitating the analysis of the potential heterogeneity of photosynthetic patterns across a produce or the rapid and simultaneous screening or phenotyping of multiple plants. At the very beginning of this development, the studies focussed on the exact evaluation of the 'topography of photosynthetic activity' (Omasa et al. 1987, Daley et al. 1989). In-depth analysis of the spatial-temporal evolution of photosynthesis of $\mathrm{CF}$ images, occasionally by advanced statistical approaches, is still of great importance for the investigation of, e.g., pre- and postharvest disease development (Scholes and Rolfe 1996, Nedbal et al. 2000c, Chaerle et al. 2007, Bauriegel et al. 2010, 2011; Bauriegel and Herppich 2014) or for phenotyping, e.g., during plant breeding (Baker and Rosenqvist 2004, Bauriegel et al. 2014, Brabandt et al. 2014), for pesticide testing (Weber et al. 2017, SánchezMoreiras et al. 2020), and others (Forstreuter et al. 2006, Kuckenberg et al. 2008, Gorbe and Calatayud 2012, Sandmann et al. 2018, Dong et al. 2019, Lu and Lu 2020). On the other hand, CFI provides a simple means to obtain, with a single measurement, the true means of distinct relevant $\mathrm{CF}$ parameters over the entire fruit or vegetable if no specific spatial patterns are relevant (Schlüter et al. 2009, Herppich et al. 2012, Baier et al. 2014, 2015; Kurenda et al. 2014, Zsom et al. 2020).

What kind of parameters to be analysed, depends on the specific needs and the focus of the study. If the latter is on the evaluation of the distinct photosynthetic responses to a particular biotic or abiotic stressor, then a comprehensive analysis of dark- and light-adapted CF is appropriate. In this context, Dong et al. (2019) determined the full spectrum of CFA parameters, including maximum and actual photochemical efficiency and all different relevant quenching coefficients to closer characterise the spatial heterogeneity of leaves of tomato seedlings to chilling stress. Such an approach provided in-depth insight into physiological mechanisms. It is, however, much more complex and relatively time consuming. This may be the reason why most other studies concentrate on the rapid measurement of dark-adapted fluorescence parameters $\left(\mathrm{F}_{0}\right.$, $\left.\mathrm{F}_{\mathrm{m}}, \mathrm{F}_{\mathrm{v}}, \mathrm{F}_{\mathrm{v}} / \mathrm{F}_{\mathrm{m}}\right)$.

\section{Application of CFI for postharvest handling}

Postharvest decay: Storage diseases of fresh or minimally processed produce may affect postharvest quality, lead to considerable losses, and consequently largely reduces economic success. Decay often starts shortly after postharvest handling, and this is difficult to detect by visual inspection. The timely evaluation of developing diseases gives the possibility to early separate infected produce, thus, minimising negative effects and decay. Particularly novel chlorophyll fluorescence- or hyperspectral-based imaging systems proved to be effective for the rapid detection of the gradual evaluation of postharvest decay at the multiple stages of postharvest handling.

Nedbal et al. (2000b) were among the first to apply a commercial PSII chlorophyll fluorescence imaging system to evaluate postharvest development and decay on lemon [Citrus limon (L.) Osbeck] fruit. The analyses of $\mathrm{CF}$ images revealed that photosynthesis remains active during fruit ripening. Moreover, with this technique, the authors monitored the temporal and the spatial dynamics of infection with green mould (Penicillium digitatum) spreading over the fruit within four days, indicated by the increase in $\mathrm{F}_{0}$ and a decrease in $\mathrm{F}_{\mathrm{v}}$. The authors found that analysing the $F_{0} / F_{v}$ ratio provided the best differentiation between healthy and infected fruit surface areas. They also pointed out the great potential of CFI to identify infected and poor-quality fruit in automated sorting lines, even long before visible damage became obvious.

A unique imaging technique was developed by Ariana et al. (2006) to classify various disorders on fruit of three apple cultivars. As the base for pixel-wise differentiation between healthy and defected fruit, the authors acquired 18 different images with a combination of filter sets and three imaging modes (reflectance, visible light-induced fluorescence, and UV-induced fluorescence) for each apple. Two classification models were developed and tested; a two-class model to categorise into normal or disordered tissue, and a six-class model to separate healthy, bitter pit, black rot, soft scald, superficial scald, and decayed tissues. Both approaches yielded high accuracy, ranging between 93 and 100\%, indicating the high potential of this specific complex imaging technique to recognise and to differentiate between various types of apple disorders.

With the help of CFI, Žabka et al. (2006) proved that the host-selective fungal toxin roseotoxin B (produced by Trichothecium roseum) at various concentrations may penetrate apple peels, damage the tissue by destroying cells 
and, finally, produce chlorotic lesions. These damaged surface areas could easily be quantified by CFI. Similarity of results indicated that the mechanisms of roseotoxin B function are very similar to those of destruxins, i.e., mycotoxins produced by another fungal pathogen, Alternaria brassicae, active on canola.

Looking for a fast and reliable system for the early detection of apple infection with Neofabraea malicorticis (bull's-eye rot), Pieczywek et al. (2018) comparatively tested biospeckle (Zdunek and Herppich 2012, Kurenda et al. 2014), hyperspectral and CF imaging. All three imaging techniques identified infected areas within only two days after inoculation and, thus, two to three days faster than visual inspection. However, from the presented results, the authors believed that the complex 'spatial visualisation of biospeckle activity' provided more detailed 'information than hyperspectral imaging' on and somewhat 'earlier detection of the infection' than CFI.

In strawberries, the actual fruit are the indehiscent achenes, visible on the surface of the receptacle-derived fleshy part of the accessory fruit. During development, colour of this 'fruit' body changes from green to red with the degradation of chlorophylls and the accumulation of anthocyanins. Strawberry achenes, however, often retain their green colour, which suggests incomplete chlorophyll decomposition and the presence of some photosynthetic capacity. With CFI, Meyerhoff and Pfündel (2008) demonstrated that PSII are still functioning in strawberry achenes. Although photosynthesis is assumed to contribute to the carbon balance in 'green-ripe' fruits, it is unclear, if it is capable to support seed development in achenes. Nevertheless, the onset of decline in their photosynthetic activity and that of the sepals, may help to objectively identify the loss of freshness.

As evaluated by CFI in peduncles of stored sweet cherries (Linke et al. 2010), $\mathrm{F}_{\mathrm{v}} / \mathrm{F}_{\mathrm{m}}$ rapidly started to decline in parallel with rapid water loss-induced degradation of photosynthetic activity (Fig. 2). As revealed by timetemperature analyses and deduced from multiple linear

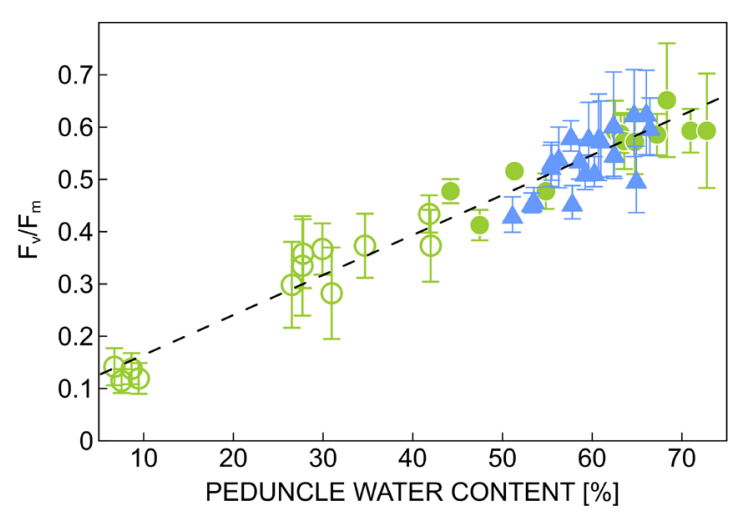

Fig. 2. Means ( $\pm \mathrm{SD}, n=7)$ of fresh mass-based water contents of attached (closed symbols) and detached peduncles (open symbols) and potential maximum photochemical efficiency $\left(\mathrm{F}_{\mathrm{v}} / \mathrm{F}_{\mathrm{m}}\right)$ of 'staccato' sweet cherry fruit stored at $21^{\circ} \mathrm{C}$ for $6 \mathrm{~d}$ (circles) and at $1^{\circ} \mathrm{C}$ for $28 \mathrm{~d}$ [triangles; after Linke et al. (2010)]. correlation and regression analysis, senescence, and other slow temperature-dependent metabolic processes had much less effects ( $23 v s .77 \%$ for water content) on these changes. Thus, variations in photosynthetic capacity of sweet cherry fruit peduncles rapidly and noninvasively indicate losses of freshness, similarly to that of strawberry achenes and sepals, indicating that CFI is very helpful in the evaluation of this important postharvest quality parameter.

Two specific indices based on either hyperspectral (three bands) or on chlorophyll fluorescence imaging showed to be able to detect both decay and freeze damage on fresh-cut lettuce (Simko et al. 2015). On red, dark green, green, light green, and yellow leaves, accuracy of classifying into fresh or decayed was almost $97 \%$, but, of course, decreased, when used on tissue with a low chlorophyll content. Very positively, both above indices can be obtained without opening the MA (modified atmosphere) bags (Herppich et al. 2012).

Nevertheless, from the above examples, it is obvious that CFI, in contrast to CFA, is given surprisingly little attention in the monitoring of postharvest quality of horticultural products. The reason for this is not clear and its evaluation is beyond the scope of this review.

Continuous weak illumination for fruit and vegetable storage: Besides advanced storage conditions, optimised packaging may effectively preserve the quality of highly perishable fresh fruit and vegetables, reduce the risk of mechanical damage, largely prevent water losses and lower respiration. In particular, modified atmosphere packaging (MAP), which establishes low $\mathrm{O}_{2}$ and high $\mathrm{CO}_{2}$ concentrations within the package by using films with specific permeabilities for these gases, may also inhibit tissue browning and microbial decay. Minimally processed fresh-cut salads and fruit may better retain their physiological activity and, therefore, their internal quality in such a specific environment.

During storage, but most of all in the display cabinets in shops, quality of fruit and vegetables is further interactively affected by temperature and by the illumination system used (Prange and Lidster 1991, Herppich 2003, Kong et al. 2021). The positive effects of low-light treatment have become increasingly obvious since LED facilitated the controlled postharvest application of low photosynthetic photon fluxes during recent years (Nassarawa et al. 2021). CFI analyses easily and noninvasively verified that optimised low illumination indeed improved quality maintenance of packed photosynthetic active corn salad, arugula, and spinach leaves (Herppich 2003, Herppich et al. 2012, Gergoff Grozeff et al. 2013) by reducing microbial decay and leaf senescence during $10 \mathrm{~d}$-storage at $18^{\circ} \mathrm{C}$. In particular, the latter is indicated by the much higher mean $F_{v} / F_{m}$ of leaves stored under weak illumination (Fig. 3). Low photosynthetic active photon fluxes [approx. $15 \mu \mathrm{mol}$ (photon) $\mathrm{m}^{-2} \mathrm{~s}^{-1}$ ] controlled the gas composition within the packaging by inducing low photosynthetic activity in these leafy greens, without excessive heat input. It, thus, reduced mitochondrial respiration, effectively preserving value-adding substances and retaining 
stored illuminated

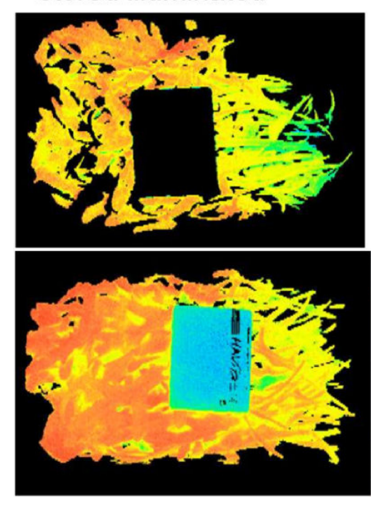

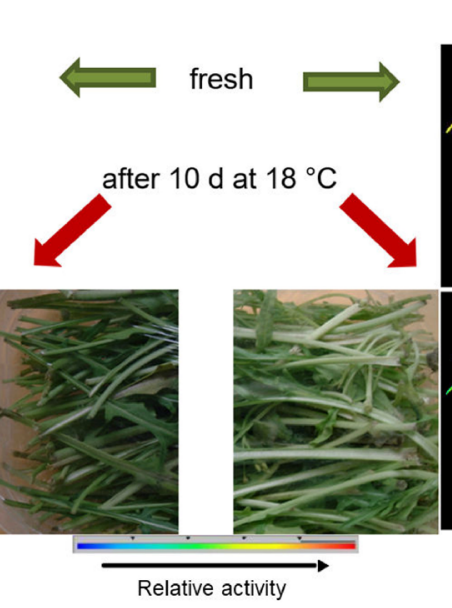

stored in darkness

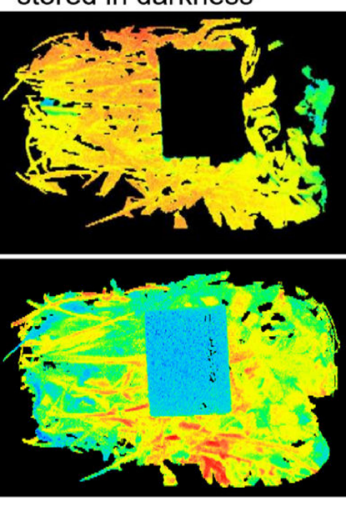

Fig. 3. False colour images indicating the differential effects of continous illumination [PPFR approx. $15 \mu \mathrm{mol}(\mathrm{photon}) \mathrm{m}^{-2} \mathrm{~s}^{-1}$ ] $\operatorname{compared}$ to darkness on the potential photosynthetic efficiency of PSII as an indicator of the mean quality of packed arugula (package labels are seen by squares covering part of the produce) during a $10-\mathrm{d}$ storage at $18^{\circ} \mathrm{C}$. The colour scale below the images indicates the relative photosynthetic activity. Given are also RGB images to illustrate the fungal infection as visible (as greyish surface cover) on some cut ends of petioles of dark stored (right hand) samples [after Herppich et al. (2012)].

the quality of fresh and fresh packed products (Prange and Lidster 1991, Herppich 2003, Hasperué et al. 2016, Kong et al. 2021). In contrast, higher photon fluxes may increase temperatures inside the packaging and, thus, might even reduce product quality (Ferrante et al. 2004, 2008). But this response seems to be species-specific (Zhan et al. 2012).

Fruit development during storage: For the optimisation of postharvest quality maintenance, e.g., during or after storage, and for the parametrisation of shelf-life prediction models, produce development in response to the respective relevant environmental conditions needs to be exactly evaluated.

In this context, the spatial and temporal dynamics of colour changes from green to red due to chlorophyll degradation and carotenoid (capsanthin) synthesis and their variation by various storage conditions were nondestructively studied on green-ripe to full-ripe fruit of the sweet pepper cultivar 'Kárpia' F1 (Zsom et al. 2010, Herppich et al. 2012). The changes of whole fruit $\mathrm{F}_{\mathrm{v}} / \mathrm{F}_{\mathrm{m}}$ (and also $F_{0}, F_{m}, F_{v}$ ) characterised the dynamics of the decline in photosynthesis (average $\mathrm{F}_{\mathrm{v}} / \mathrm{F}_{\mathrm{m}}$ declined from approx. 0.55 to 0.05 ) and chlorophyll content in the fruit body and indicated that this was completely independent of the accumulation of capsanthin, as evaluated by RGBimaging. On the other hand, the stalks retained their high photosynthetic activity. At $18^{\circ} \mathrm{C}$, capsanthin synthesis proceeds very fast and may completed within one day as indirectly indicated by the changes in the red-to-green colour ratio (Fig. 4). Chlorophyll, however, degrades only slowly within 4 to $5 \mathrm{~d}$ after the fruit had become fully red. As this is valid for packed and unpacked fruit, low storage temperature but much less so modified atmosphere packaging (i.e., low $\mathrm{O}_{2}$ and high $\mathrm{CO}_{2}$ concentrations within a package) can affect ripening and hence, changes in both pigments (Zsom et al. 2010).
In red-pigmented cultivars of, e.g., apples and peaches, chlorophyll content and its degradation are not easily assessable, but can be completely masked by anthocyanins in the epidermis of such fruit. Bodria et al. (2004) deve-

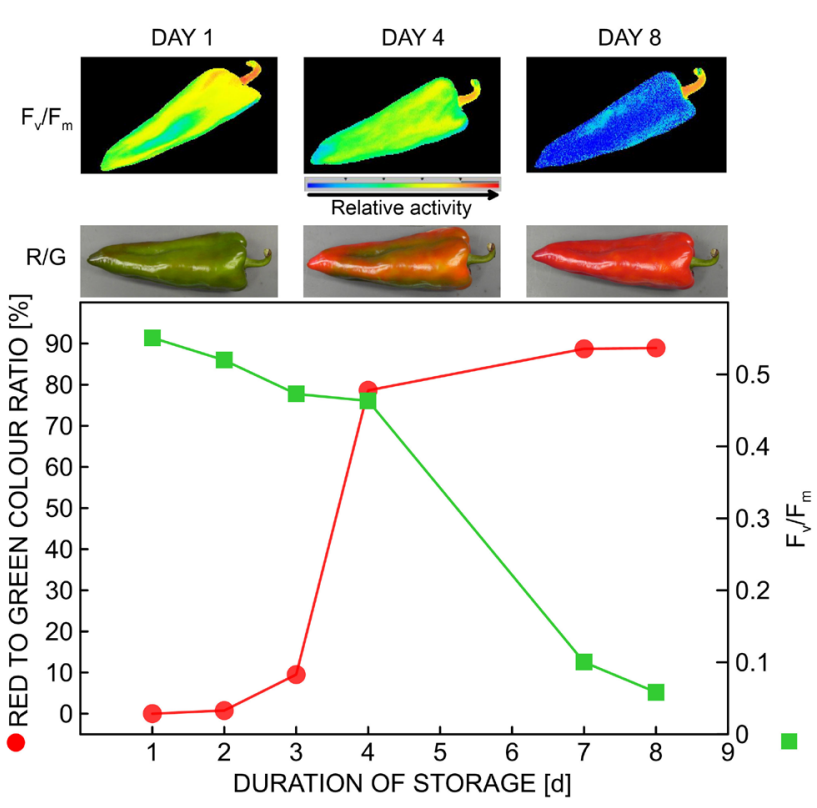

Fig. 4. Dynamic changes of sweet pepper chlorophyll as indirectly indicated by the means of the potential maximum photochemical quantum efficiency of PSII $\left(\mathrm{F}_{\mathrm{v}} / \mathrm{F}_{\mathrm{m}}\right)$ and carotenoid contents as indicated by the $\mathrm{R} / \mathrm{G}$ ratio (obtained by pixelwise analyses of the relative contribution of the respective colour band of RGB images) during fruit development in dark-storage at approx. $18^{\circ} \mathrm{C}$ and $90 \%$ relative humidity, as shown by a time-series of images (examples of $\mathrm{F}_{\mathrm{v}} / \mathrm{F}_{\mathrm{m}}$ and of RGB images taken on days one, four and eight are given) of a representative sample [after Herppich et al. (2012)]. 
loped a UV-blue light-equipped fluorescence imaging system to evaluate the development of 'Red Delicious' apples as means for the optimisation of harvest and postharvest management. The authors also used this technique to nondestructively estimate changes in fruit firmness and sugar content during storage. Similar results were obtained in peach and nectarine cultivars with chlorophyll fluorescence excited by red actinic light though the fluorescence had a lower intensity.

With standard CFA and CFI technique, Zdunek and Herppich (2012) evaluated the potential interactions between biospeckle activity studied with lasers of various wavelengths, and photosynthetic activity and chlorophyll content in apples. Normally, red lasers are used for biospeckle, a wavelength range that is absorbed by chlorophyll, which may affect light propagation and biospeckle activity. For apples, the biospeckle activity indeed largely depended on chlorophyll contents. Light absorption by chlorophyll masks the movement of particles, which is reflected by biospeckle, thus, resolution of this techniques could increase with chlorophyll degradation during fruit ripening.

Noh and Lu (2007) assumed that fluorescence kinetic analysis is not satisfactory for fruit quality evaluation. Thus, they applied hyperspectral imaging of continuous wave blue (408 nm) laser-induced fluorescence scattering images to predict multiple quality parameters of 'Golden Delicious' apples. A multitude of statistical pre-processing and analytical techniques (PCA, neural network modelling) were used to develop models for the prediction of fruit quality parameters. Although prediction quality of the distinct parameters was high, the authors assumed that hyperspectral laser-induced fluorescence imaging may potentially be useful for assessing selected quality parameters of apples.

In a study on chlorophyll fluorescence imaging in bunches of 'Sangiovese' grapes (Vitis vinifera L.), Agati et al. (2008) measured the distribution of anthocyanins using two bands (550 and $650 \mathrm{~nm}$ ) of excitation light in sequence. In images of logarithms of fluorescence signal ratios, pixel intensities could be exponentially related to the anthocyanin concentrations, as determined in berry extracts. From this, the heterogeneity of anthocyanin concentrations in the different berries of the bunches could be analysed. Thus, this technique may potentially be helpful to evaluate the effects of physiological and environmental factors on pre- and postharvest development of grapes.

Chilling injury: Fruits and vegetables are still living and physiologically active after harvest. Continuing respiration, transpiration, heat production, etc. significantly affect their shelf-life and renders them extremely sensitive and perishable. Since long, cool storage is known to efficiently retard life processes and maintain quality, however, in a very produce-dependent manner. Mostly fruits and vegetables of tropical or subtropical origin are sensitive to low $\left(<10^{\circ} \mathrm{C}\right)$, nonfreezing temperatures. In sensitive produce, these practical cold temperatures during storage, sorting, transportation or shipping may induce serious chilling injuries (CI).
Chilling injury denotes a physiological disorder, at all metabolic levels, including membranes, reactive oxygen species or transcription (Parkin et al. 1989, Sevillano et al. 2009, Lukatkin et al. 2012). The expression of CI depends on the severeness and the duration of cold treatment, and on the physiological status and the maturity stage of the produce. Several postharvest treatments (producedependent time-temperature management, short-time heat treatments) may reduce and/or alleviate symptoms of chilling injuries. Typically, CI symptoms become severely visible only in retail after removal from chilled conditions and negatively affects produce quality and marketability (Sevillano et al. 2009, Aghdam and Bodbodak 2014). The major mechanisms of CI make photosynthesis a primary target in photosynthetically active produce and, consequently, CFA a very useful rapid noninvasive indicator (Tijskens et al. 1994). Chlorophyll fluorescence analysis and less so CFI have indeed widely been used for the evaluation of CI effects (Tijskens et al. 1994, Purvis 2002, Kosson 2003, Zsom et al. 2018, Oseko et al. 2020).

In sweet peppers or paprika (Capsicum annuum L.), for example, improper storage at temperature below $8^{\circ} \mathrm{C}$ may occasionally induce chilling injury, especially in unripe and semi-matured fruits (Lim et al. 2007, Zsom et al. 2020). In addition, in such fruits, postharvest ripening may be delayed and partly retarded in shelf-life after chilling, however, without any characteristic visible symptoms of chilling injury. Applying CFI and other nondestructive monitoring techniques, Zsom et al. (2020) evaluated the temporal and spatial dynamics of chilling development in green, semi-ripe fruit of a 'kápia' type sweet pepper cultivar (Kapitány F1) stored at low temperatures (2.5, 5 , and $10^{\circ} \mathrm{C}$ for $7 \mathrm{~d}$ ) and during shelf-life. Without any clear patchy response, monitored $\mathrm{CF}$ parameters $\left(\mathrm{F}_{0}, \mathrm{~F}_{\mathrm{m}}\right.$, and $\mathrm{F}_{\mathrm{v}} / \mathrm{F}_{\mathrm{m}}$ ) slightly but significantly declined only during storage at $2.5^{\circ} \mathrm{C}$, and rapidly and pronouncedly but with similar dynamics in all samples during subsequent shelflife at room temperature. Interestingly, no direct visible symptoms (e.g., surface pitting, sunken areas) became obvious on the presumedly chilling-stressed fruit. Changes of CF parameters during shelf-life, thus, reflected normal and undisturbed maturation-related degradation of the photosynthetic apparatus and of chlorophyll, as also detected by spectral analyses.

In contrast to sweet pepper, green-ripe banana fruit are much more chilling-sensitive and develop all associated CI symptoms when stored below a threshold temperature of approx. $10^{\circ} \mathrm{C}$ (Zsom et al. 2018). The results of Zsom et al. (2018) revealed that storage (for $8 \mathrm{~d}$ ) at temperatures below this threshold reduced mass loss, respiration, and ethylene biosynthesis of fruit but also induced unique visible symptoms (smoky peel surface discoloration, dark-brown streaked subepidermal tissue discoloration). After three days of cold storage, $\mathrm{F}_{0}, \mathrm{~F}_{\mathrm{m}}$, and $\mathrm{F}_{\mathrm{v}}$ started to decline temperature-dependently, at 2.5 and $5^{\circ} \mathrm{C}$, but not at 10 or $15^{\circ} \mathrm{C}$. This effect further accelerated during shelflife and $F_{m}$ and $F_{v}$ obtained nearly the same low values in all samples after $8 \mathrm{~d}$ of shelf-life. In contrast, the average initial $\mathrm{F}_{\mathrm{v}} / \mathrm{F}_{\mathrm{m}}$ (approx. 0.65), typical for mature green intact bananas, was less sensible and only insignificantly 
changed during storage at chilling temperatures but did so during fruit maturation in shelf-life.

Using a self-assembled CFI system with sinusoidallymodulated structured UV-blue excitation light (400 \pm $35 \mathrm{~nm}$ ), Lu and $\mathrm{Lu}$ (2020) examined the chilling responses of cucumber fruit. That way, they obtained CF images at both 675 and $750 \mathrm{~nm}$. An automated vignetting correction, which applies a bidimensional empirical mode decomposition technique improves sharpness and contrast of those images. This approach enhanced differentiation between healthy and chilling-injured subsurface tissue, thus facilitating detection of e.g., chilling-induced surface lesions. In practice, such a system may advance the discrimination between healthy and pronouncedly chilling injured fruit on sorting lines before their further processing after cold storage.

From the examples of CFI analyses and also from the CFA studies cited above, it is obvious that this technique is helpful in the evaluation of the spatial and temporal dynamics and the degree of CI symptom development in all photosynthetically active produce, provided they are actually CI sensitive. This fact itself, however, can also easily be analysed especially with CFI, if such a device is available to researchers.

\section{Evaluation of new gentle sanitation techniques}

The outbreaks of serious and occasionally lethal infections due to the consumption of fresh produce contaminated with pathogenic microorganisms (RKI 2011, CDC 2012), but also the increasing need to reduce phytopathogeninduced food waste, highlighted the importance to develop new and/or to optimise yet existing sanitation techniques for effective control and elimination of microbial loads of fresh and minimally processed fruit and vegetables. Currently, quite often chemicals such as chlorine are applied for sanitation, which include the risk of forming carcinogenic by-products (Brungs 1973, Wei et al. 1985). Consequently, new, advanced and effective approaches, based on physical methods, are needed that safely reduce microbial loads without negatively affecting product quality (Baier et al. 2015, Deng et al. 2020).
Cold atmospheric plasma treatment: Nonthermal nonequilibrium plasma (or cold atmospheric plasma, CAP) is one promising physical technique. CAP is usually generated by exposing process gas to a strong electric field at, or above or below atmospheric pressure, which partially ionises the gas molecules and concomitantly induces the formation of ions and radicals, heat (gas temperature less than $500 \mathrm{~K}$ ), and UV radiation. This all together might affect microbes, adherent to the food surfaces (Schlüter et al. 2013, Ehlbeck et al. 2015). Many studies proved the broad antimicrobial effects of CAP under both laboratory (Fröhling et al. 2012, Schnabel et al. 2012) and under practical conditions on the surfaces of fresh food (Critzer et al. 2007, Hertwig et al. 2015a,b; Bovi et al. 2019). However, very little is still known about the potential interactions between CAP and physiology and quality of treated fresh products. The considerable differences between the types of plasma sources used and their mode of application (direct treatment, remote exposure) also impeded the comparability of previous results. To provide basic information for the optimisation of process settings, Baier et al. (2013, 2014, 2015) comprehensively studied the impacts of plasma treatments of different energy and various durations on the photosynthetic activity of several horticultural products, using chlorophyll fluorescence image analysis.

As shown by Baier et al. (2013), even highly perishable lamb's lettuce (Valerianella olitoria Poll.) leaves used as model produce tolerate direct exposure to plasma, generated at $10 \mathrm{~W}$ power, for up to $5 \mathrm{~min}$ without any measurable or visible damage. Although mean $F_{v} / F_{m}$ slightly declined immediately after the treatment, it fully recovered within one day of storage. Furthermore, application of CAP generated at $20 \mathrm{~W}$ diminished the photosynthetic activity of leaves only when treatments were extended to more than 1 min (Fig. 5). Under these processing conditions, the leaf surface, within $1 \mathrm{~min}$, obtained a potentially stressing temperature of $44^{\circ} \mathrm{C}$ (Havaux 1992, Pastenses and Horton 1999, Schlüter et al. 2008, 2009). This temperature, however, slightly declined during the prolonged treatment (i.e., $>1 \mathrm{~min}$ ), while losses of photosynthetic competence became permanent.
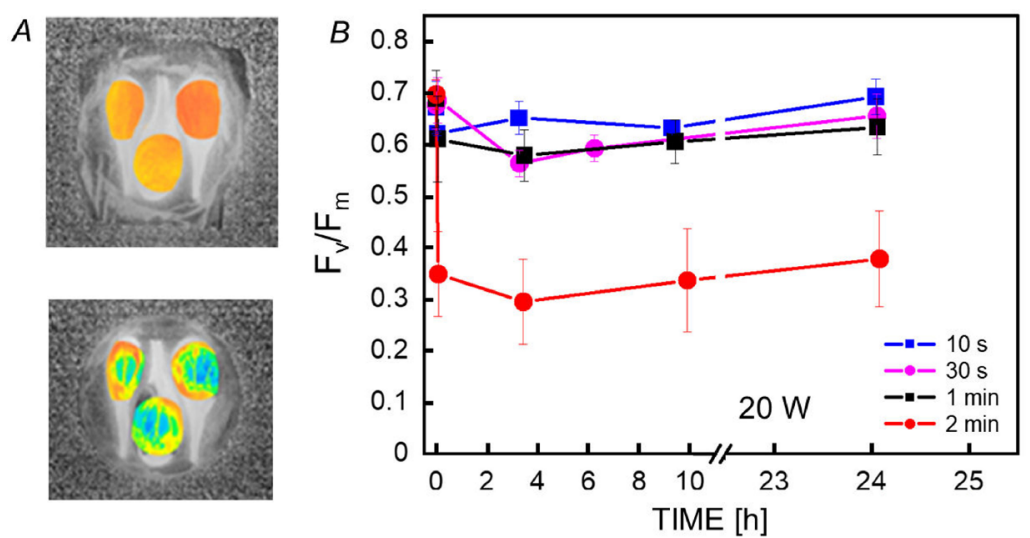

Fig. 5. (A) False-colour images and $(B)$ means $( \pm \mathrm{SD}, n=9)$ of the maximum photochemical efficiency of PSII $\left(\mathrm{F}_{\mathrm{v}} / \mathrm{F}_{\mathrm{m}}\right)$ of lamb's lettuce (Valerianella olitoria Poll.) leaves before $(\mathrm{t}=0)$ and during $24 \mathrm{~h}$ after plasma jet treatment at 1 -cm distance, $20 \mathrm{~W}$ generator power, and a gas flow rate of $20 \mathrm{~L} \mathrm{~min}^{-1}$ [after Baier et al. (2013)]. 
In addition, $10 \mathrm{~W}$-CAP treatments longer than $5 \mathrm{~min}$ started to inhibit $F_{v} / F_{m}$, while leaf temperatures clearly remained below $40^{\circ} \mathrm{C}$. This suggests that photosynthesis was mainly or even exclusively affected by the action of plasma components other than heat. In the context of CAP treatments, UV radiation, ozone, reactive oxygen species (ROS) or various nitrogen oxides are strong oxidants and prominent candidates for the above-mentioned active plasma components (Brandenburg et al. 2007, 2009; Weltmann et al. 2008).

Particularly UV radiation is widely applied as an effective (Brandenburg et al. 2007) alternative bacteriatargeted surficial sanitation technique in food processing (Allende and Artés 2003). Although UV inhibits photosynthesis in leaves of unadapted plants (Allen et al. 1998, Krause et al. 2003), even long-term exposure to UV-B did obviously not affect photosynthetic competence and productivity of crops or natural vegetation (Allen et al. 1998). Reactive oxygen species largely contribute to the overall bactericidal effects of plasma by their wellcharacterised impacts on bacterial membrane components (Mendis et al. 2000, Kong et al. 2009). Plasma treatments also degrade the layers of epicuticular waxes of lamb's lettuce leaves (Grzegorzewski et al. 2010), which exposes the unprotected epidermis to prolonged plasma application.

At generator powers of $30 \mathrm{~W}$ and higher, the combination of thermal stress and more intensive plasma became harsh and irreversibly impaired the photosynthetic activity of the treated leaves within the shortest times. Thus, the CFI analysis clearly indicated that direct CAP application is limited for fresh produce sanitation treatments at generator powers of 10 and $20 \mathrm{~W}$ for 5 and $1 \mathrm{~min}$, respectively, which seems to be below the limit for antimicrobial efficacy (Deng et al. 2005, Fröhling et al. 2012).

In addition, CFI was applied to analyse the effects of different source gases (air, with or without addition of oxygen, noble gases) and of distinct spatial operation parameters (diameter of the plasma torch; distance between jet and object) of direct treatments with plasma jet systems (Baier et al. 2014). The significantly lower $\mathrm{F}_{\mathrm{v}} / \mathrm{F}_{\mathrm{m}}$ verified that a highly focused plasma stream (diameters of $1 \mathrm{~mm}$ ) more pronouncedly inhibited the photochemical efficiency of treated lamb's lettuce leaves than a broader plasma-jet (diameter of $7 \mathrm{~mm}$ ). As expected, enhancing the distance between the filament and the leaf surface from 10 to $12 \mathrm{~mm}$ similarly reduced the negative effects of the plasma treatment on the photosynthetic activity.

Furthermore, the potential impacts of several other plasma techniques on the photosynthetic activity of perishable products were evaluated with the help of chlorophyll fluorescence imaging (Baier et al. 2014, 2015). Treatment of lamb's lettuce leaves with either pulsed surface dielectric barrier discharge (SDBD) plasma and also with indirect microwave-induced air plasma within a remote exposure reactor led to severe losses of maximum photochemical efficiency. Additional visual inspections showed that SDBD-treated lamb's lettuce leaves maintained their green colour and tissue elasticity but had a pronounced altered appearance, resembling a superficial mechanical injury. Interestingly, also bulky fruit (apples, cucumbers, tomatoes, and carrots) with lower surface to volume ratio providing smaller plasma contact area could not better tolerate respective applications (Baier et al. 2015).

In general, CFI analyses highlighted that the plasmajet treatments significantly better retained physiological activity and, thus, produce quality than SDBD or indirect plasma treatments. From the practical view, CFI analyses deepen the knowledge on the mechanisms of action and, thus, facilitate the optimisation of relevant process parameters (generator energy, exposure distance and systems, process gas composition and thus concentration of plasma species) to improve the capabilities of innovative plasma techniques for nondestructive sanitation of perishable produce.

High hydrostatic pressure treatments: As summarised by Rux et al. (2017, 2019, 2020), the food industry increasingly applies high hydrostatic pressure (HHP) as efficient but gentle nonthermal sanitation technique for various preservation and processing purposes. HHP treatments effectively inactivate microorganisms, while retaining vitamins, pigments, and flavour of the produce. Due to the pronounced diversity in form, function, and sensitivity of fruits and vegetables, HHP, on the other hand, could highly specifically and differentially affect their membrane, protein, and enzyme functionality, i.e., their overall metabolic activity and their structures (Indrawati et al. 2000, Marigheto et al. 2004, Knorr et al. 2006, Trejo Araya et al. 2007, Schlüter et al. 2009, Vargas-Ortiz et al. 2013, Rux et al. 2017, 2019, 2020).

In this context, by CFI analyses, Schlüter et al. (2009) evaluated the effects of HHP on the photosynthetic activity of lamb's lettuce leaves as a model produce. Combining a large number of complex and highly regulated biophysical and biochemical reactions, photosynthesis serves as an ideal sensitive indicator of the overall metabolic activity. The temporal dynamic of changes in $\mathrm{F}_{\mathrm{v}} / \mathrm{F}_{\mathrm{m}}$ after treatments at a large range of $\mathrm{HHP}$ at various pressure holding-times indicated $100 \mathrm{MPa}$ and $10 \mathrm{~min}$ as critical parameters. In plants exposed to HHP beyond these critical values, photosynthetic activity continued to slowly decline irreversibly after an initial drop. This immediate effect on $\mathrm{F}_{\mathrm{v}} / \mathrm{F}_{\mathrm{m}}$ increased with HHP and pressure holding-time, while the ability to recover from the stress decreased. A treatment pressure of $200 \mathrm{MPa}$ for only $2.5 \mathrm{~min}$ completely damaged the photosynthetic apparatus.

From the close similarity of these results to the irreversible loss of membrane integrity effects after heat treatments, the authors concluded that the integrity of the photosynthetic membranes was the primary high-pressure target. In this context, Yu et al. (2001) also reported the release of the extrinsic proteins of the photosynthetic oxygen-evolving complex from PSII membranes as an initial high-pressure response of photosynthesis. Later, by evaluation of impacts on tissue turgor and elasticity, reflecting sensorial firmness and general texture, integrity, and function of biomembranes have been confirmed as the initial targets of HHP treatments, partially reversibly affecting their permeability (Schlüter et al. 2009, Rux et al. 
$2017,2019)$. Only if the function of relevant membraneassociated proteins is disturbed at HHP higher than $150 \mathrm{MPa}$, the pressure-induced changes become irreversible (Rux et al. 2019) and produce appearance and texture negatively affected.

It seems reasonable to assume that thin and soft lamb's lettuce leaves as used by Schlüter et al. (2009) for their experiments are particularly sensitive to HHP treatments. Large fruit such as apples are much more compact and might probably withstand higher pressures or longer pressure-holding times. However, Kurenda et al. (2014) reported that HHP treatments at $100 \mathrm{MPa}$ applied for $10 \mathrm{~min}$ resulted in both a significant immediate and a long-lasting decline of mean $\mathrm{F}_{\mathrm{v}} / \mathrm{F}_{\mathrm{m}}$ over the entire fruit surface. The decline in $\mathrm{F}_{\mathrm{v}} / \mathrm{F}_{\mathrm{m}}$ further continued during seven days of dark storage at room temperature. These changes in the photosynthetic competence were closely accompanied by the reduction of light absorption at both 635 and $690 \mathrm{~nm}$, indicating the HHP induced degradation of chlorophylls. This may indicate that the irreversible damage of membranes and of the entire photosynthetic apparatus ends up in the complete disintegration of the tissue functionality. These effects were, again, more pronounced the higher the applied pressure.

All the above findings and the fact that the efficient decontamination of bacteria, fungi or viruses requires pressures beyond $300 \mathrm{MPa}$ certainly questioned the meaningful application of HHP for sanitation of fresh perishable produce (Schlüter et al. 2009, Kurenda et al. 2014, Rux et al. 2017, 2019, 2020).

Heat treatments: Recent practical preservation techniques applied to guaranty safety, high quality, and long shelf life of fresh and minimally processed fruits and vegetables also include various types of postharvest heat treatments. Exposure of produce to either hot air, steam, or hot water (usually at $\mathrm{T}<60^{\circ} \mathrm{C}$ ) for few seconds to hours may result in superficial disinfection. However, it may also induce complex physiological protection responses, e.g., changes in protein expression, membrane composition and fluidity, hormone homeostasis, cytoskeleton stability, and chromatin modifications, and may elicit the expression of heat shock and pathogenesis-related proteins (Lurie 1998, Bokszczanin et al. 2013, Kabelitz et al. 2019). Since many years, heat treatments have been successfully applied on various fruits (e.g., apples, peaches, grapefruits, bananas, and mangos) and few vegetables for both effective control of fungal and insect infestations but also for improvement of storability and maintenance of quality (Lurie 1998, Trierweiler et al. 2003, Shao et al. 2007, Kabelitz and Hassenberg 2018).

In this context, hot water treatment (HWT) is a promising rapid and relatively inexpensive easy-to-use technique. This gentle, safe, and chemical-free sanitation technique is, furthermore, suitable for both conventionally and organically produced fruits and vegetables (Kabelitz and Hassenberg 2018, Kabelitz et al. 2019). The temperature and time window between optimal positive and damaging effects of the application is, however, often small for HWT. Because photosynthesis is very sensitive to heat and the relevant effects are well-explored since many years (Krause and Weis 1991, Hüve et al. 2011, Matyssek and Herppich 2018), CFI rapidly and comprehensively characterises the respective temperature effects on green fruit and vegetables (Schlüter et al. 2009, Kurenda et al. 2014, Herppich et al. 2020).

Although HWT is preferably applied to fruit, it has been also used for few leafy greens such as wild rocket, spinach, lettuce, and lamb's lettuce (Koseki and Isobe 2006, Glowacz et al. 2013, Szwejda-Grzybowska et al. 2019). A detailed analysis of the photosynthetic responses of fresh harvested leaves of the latter species to heat in hot water (Schlüter et al. 2009) showed that even short (> $30 \mathrm{~s}$ ) applications of moderately high temperatures (e.g., $\left.45^{\circ} \mathrm{C}\right)$ reversibly and, to a minor extent $(<15 \%)$, inhibited $\mathrm{F}_{\mathrm{v}} / \mathrm{F}_{\mathrm{m}}$. Although the ability of these lamb's lettuce leaves to recover during a 24-h dark relaxation period declined the longer the duration of the treatment, it was still partially $(39 \%)$ reversible even after $10 \mathrm{~s}$ at the lethal (e.g., Bilger et al. 1984) temperature of $50^{\circ} \mathrm{C}$, but not beyond. This points out the very narrow gap between inhibition and damage of the photosynthetic machinery. Very similar to the effects of high hydrostatic pressure (Yu et al. 2001, Schlüter et al. 2009), excessive heat affects the ultrastructure of cellular systems (Maheswari et al. 1999), damages membrane bound and solved proteins (Haltia and Freire 1995) and causes phase transition of biomembrane lipid double layer (Nauš et al. 1992). Thus, also heat stress acts on both proteins and on membranes. This renders PSII particularly heat sensitive, in contrast to other components of photosynthetic energy generation and photosynthetic carbon reduction cycle (Havaux 1992) and makes CFA and CFI a sensitive monitor of short and long-term heat effects (Krause and Weis 1991, Matyssek and Herppich 2020).

Kabelitz and Hassenberg (2018) recommended shortterm (few seconds to minutes) hot-water treatments (sHTW) as very effective and chemical-free sanitation technique for fresh-cut fruit salad production. However, these authors also stressed that, for this specific purpose, sHWT needs optimisation in terms of treatment temperature and duration for efficient sustainable inactivation of spoilage organisms and human pathogens without any adverse effects on produce. Applying CFI and spectral analyses, Herppich et al. (2020) cultivar-specifically (Shao et al. 2007) evaluated the effects of sHWT in the range of 44 to $70^{\circ} \mathrm{C}$ for 30 to $300 \mathrm{~s}$ on the photosynthetic activity of fruit of two coloured ('Braeburn' and 'Fuji') and two greenripe ('Greenstar' and 'Granny Smith') apple cultivars, practically relevant for fruit salad production.

Because sHWT in the range of up to $65^{\circ} \mathrm{C}$ for up to $60 \mathrm{~s}$ only heats the outer epidermal and subepidermal tissues (Kabelitz et al. 2019), this treatment did not influence taste, texture, and appearance of any treated apple. On the other hand, epidermal and some subepidermal tissue cells few millimetres into the fruit body indeed experienced some heat stress and inhibited photosynthetic performance beyond respective thresholds of treatment temperature and duration, although without any effect on the contents of relevant photosynthetic pigments. As expected (Shao et al. 2007), this threshold temperature range indeed varied 
between apples of the different cultivars and 'Braeburn' apples were more sensitive to sHWT than fruit of the other cultivars.

Responses of photosynthetic activity of apples to sHWT at various temperatures and durations suggest that serious damage at the cellular level may become relevant when a distinct critical heat dose was exceeded. Although heat-pulse treatments obviously yield higher temperature thresholds (Hüve et al. 2011), steady-state heating above $40^{\circ} \mathrm{C}$ for prolonged time induces more serious heat-stress symptoms even in massive apple fruit (Hengari et al. 2016). The final degree of inhibition and/or damage depends on both temperature and exposure time of the fruit (Bilger et al. 1984). This effect, however, is valid only below an effective critical temperature $\left(T_{\text {crit }}\right)$ at which $F_{v} / F_{m}$ started to decline pronouncedly but less so beyond it. In the experiment presented by Herppich et al. (2020), sHWT at $55^{\circ} \mathrm{C}$ for $120 \mathrm{~s}$ reduced $\mathrm{F}_{\mathrm{v}} / \mathrm{F}_{\mathrm{m}}$ less than exposing the fruit to $70^{\circ} \mathrm{C}$ for only $30 \mathrm{~s}$, which yielded a lower temperature dose. At the latter temperature, which is certainly well beyond $\mathrm{T}_{\text {crit }}$, the damaging effect of the heat treatment became fully irreversible.

This $\mathrm{T}_{\text {crit }}$ was found to be $55^{\circ} \mathrm{C}$ in 'Braeburn' apples (Fig. 6) and $60^{\circ} \mathrm{C}$ in fruit of the other three cultivars (Herppich et al. 2020). Thus, CFI rapidly and sensitively proved optimal to evaluate the cultivar- or batch-specificity of process parameters for sHWT of apples.

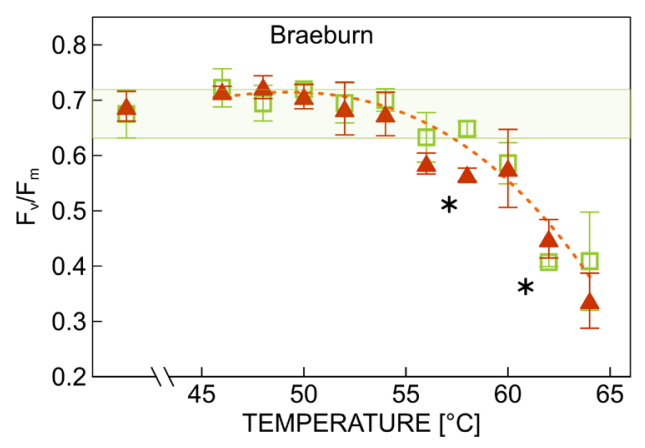

Fig. 6. Pixel-averaged means $( \pm \mathrm{SD}, n=3)$ of the potential maximum photochemical efficiency of PSII $\left(\mathrm{F}_{\mathrm{v}} / \mathrm{F}_{\mathrm{m}}\right)$, for each of the two separately analysed sides (mostly red: filled triangles; mostly greenish: open squares) of 'Braeburn' apples, hot watertreated in the range of 46 up to $63^{\circ} \mathrm{C}$ for $30 \mathrm{~s}$, fruit treated at approx. $20^{\circ} \mathrm{C}$ were used as controls. The asterisks denote significant $(p<0.05)$ differences between means [after Herppich et al. (2020)], the horizontal bar highlights the range of initial $\mathrm{F}_{\mathrm{v}} / \mathrm{F}_{\mathrm{m}}$ of the fresh fruit.

Conclusions: Chlorophyll fluorescence analysis and particularly CF imaging are powerful rapid tools to determine the preharvest and postharvest external and internal quality of green produce. CFI effectively detects the heterogeneity in photosynthetic responses and monitors the local and temporal dynamics of photosynthetic activity. Thus, CFI is especially suitable to noninvasively analyse and test the produce responses to multiple postharvest conditions, treatments, and techniques. However, despite the relative ease of measurements, knowledge of the physiological base, and of the actual limits of interpretation of the results is indispensable for a meaningful interpretation of the results to draw the correct consequences, e.g., for the adjustment and/or optimisation of postharvest handling and new techniques.

\section{References}

Abasi S., Minaei S., Jamshidi B., Fathi D.: Dedicated nondestructive devices for food quality measurement: A review. Trends Food Sci. Tech. 78: 197-205, 2018.

Abbott J.A.: Quality measurement of fruits and vegetables. Postharvest Biol. Tec. 15: 207-225, 1999.

Agati G., Fusi F., Mazzinghi P., di Paola M.L.: A simple approach to the evaluation of the reabsorption of chlorophyll fluorescence spectra in intact leaves. - J. Photoch. Photobio. B 17: 163-171, 1993.

Agati G., Traversi M.L., Cerovic Z.G.: Chlorophyll fluorescence imaging for the noninvasive assessment of anthocyanins in whole grape (Vitis vinifera L.) bunches. - Photochem. Photobiol. 84: 1431-1434, 2008.

Aghdam M.S., Bodbodak S.: Postharvest heat treatment for mitigation of chilling injury in fruits and vegetables. - Food Bioproc. Tech. 7: 37-53, 2014

Allen D.J., Nogues S., Baker N.R.: Ozone depletion and increased UV-B radiation: is there a real threat to photosynthesis? J. Exp. Bot. 49: 1775-1788, 1998.

Allende A., Artés F.: UV-C radiation as a novel technique for keeping quality of fresh processed "Lollo Rosso" lettuce. Food Res. Int. 36: 739-746, 2003.

Ariana D.P., Guyer D.E., Shrestha B.P.: Integrating multispectral reflectance and fluorescence imaging for defect detection on apples. - Comput. Electron. Agr. 50: 148-161, 2006.

Baier M., Ehlbeck J., Knorr D. et al.: Impact of plasma processed air (PPA) on quality parameters of fresh produce. - Postharvest Biol. Tec. 100: 120-126, 2015.

Baier M., Foerster J., Schnabel U. et al.: Direct non-thermal plasma treatment for the sanitation of fresh corn salad leaves: Evaluation of physical and physiological effects and antimicrobial efficacy. - Postharvest Biol. Tec. 84: 81-87, 2013.

Baier M., Görgen M., Ehlbeck J. et al.: Non-thermal atmospheric pressure plasma: Screening for gentle process conditions and antibacterial efficiency on perishable fresh produce. - Innov. Food Sci. Emerg. Technol. 22: 147-157, 2014.

Baker N.R., Harbinson J., Kramer D.M.: Determining the limitations and regulations of photosynthetic energy transduction in leaves. - Plant Cell Environ. 30: 1107-1125, 2007.

Baker N.R., Rosenqvist E.: Applications of chlorophyll fluorescence can improve crop production strategies: an examination of future possibilities. - J. Exp. Bot. 55: 1607-1621, 2004.

Bauriegel E., Brabandt H., Gärber U., Herppich W.B.: Chlorophyll fluorescence imaging to facilitate breeding of Bremia lactucae-resistant lettuce cultivars. - Comput. Electron. Agr. 105: 74-82, 2014.

Bauriegel E., Giebel A., Herppich W.B.: Rapid Fusarium head blight detection on winter wheat ears using chlorophyll fluorescence imaging. - J. Appl. Bot. Food Qual. 83: 196-203, 2010.

Bauriegel E., Giebel A., Herppich W.B.: Hyperspectral and chlorophyll fluorescence imaging to analyse impacts of Fusarium culmorum on photosynthetic integrity of infected 
wheat ears. - Sensors-Basel 11: 3765-3779, 2011.

Bauriegel E., Herppich W.B.: Hyperspectral and chlorophyll fluorescence imaging for early detection of plant diseases, with special reference to Fusarium spec. infections on wheat. Agriculture 2014: 32-57, 2014.

Bilger H.W., Schreiber U., Lange O.L.: Determination of leaf heat resistance: Comparative investigation of chlorophyll fluorescence changes and tissue necrosis methods. Oecologia 63: 256-262, 1984.

Bodria L., Fiala M., Guidetti R., Oberti R.: Optical techniques to estimate the ripeness of red-pigmented fruits. - Trans. ASAE 47: 815-820, 2004.

Bokszczanin K.L., Solanaceae Pollen Thermotolerance Initial Training Network (SPOT-ITN) Consortium, Fragkostefanakis S.: Perspectives on deciphering mechanisms underlying plant heat stress response and thermotolerance. - Front. Plant Sci. 4: 315, 2013.

Bovi G.G., Caleb O.J., Herppich W.B., Mahajan P.W.: Mechanisms and modeling of water loss in horticultural products. - In: Reference Module in Food Science 2018. Pp. 1-5. Elsevier, Amsterdam 2018.

Bovi G.G., Fröhling A., Pathak N. et al.: Safety control of whole berries by cold atmospheric pressure plasma processing: A review. - J. Food Prot. 82: 1233-1243, 2019.

Brabandt H., Bauriegel E., Gärber U., Herppich W.B.: $\Phi_{\text {PSII }}$ and NPQ to evaluate Bremia lactucae-infection in susceptible and resistant lettuce cultivars. - Sci. Hortic.-Amsterdam 180: 123-129, 2014

Brandenburg R., Ehlbeck J., Stieber M. et al.: Antimicrobial treatment of heat sensitive materials by means of atmospheric pressure Rf-driven plasma jet. - Contrib. Plasm. Phys. 47: 72-79, 2007.

Brandenburg R., Lange H., von Woedtke T. et al.: Antimicrobial effects of UV and VUV radiation of nonthermal plasma jets. IEEE Trans. Plasma Sci. 37: 877-883, 2009.

Brungs W.A.: Effects of residual chlorine on aquatic life. J. Water Pollut. Control Fed. 45: 2180-2193, 1973.

Buschmann C.: Variability and application of the chlorophyll fluorescence emission ratio red/far-red of leaves. - Photosynth. Res. 92: 261-271, 2007.

Bußler S., Herppich W.B., Neugart S. et al:: Impact of cold atmospheric pressure plasma on physiology and flavonol glycoside profile of peas (Pisum sativum 'Salamanca'). Food Res. Int. 76: 132-141, 2015.

Butz P., Hofmann C., Tauscher B.: Recent developments in noninvasive techniques for fresh fruit and vegetable internal quality analysis. - J. Food Sci. 70: R131-R141, 2005.

Caleb O.J., Herppich W.B., Mahajan P.V.: The basics of respiration for horticultural products. - In: Reference Module in Food Science 2016. Pp. 1-7. Elsevier, Amsterdam 2016.

CDC: Foodborne Diseases Active Surveillance Network (FoodNet): FoodNet Surveillance Report for 2012. Pp. 36. Department of Health \& Human Services, Atlanta 2012.

Chaerle L., Hagenbeek D., De Bruyne E., Van Der Straeten D.: Chlorophyll fluorescence imaging for disease-resistance screening of sugar beet. - Plant Cell Tiss. Org. 91: 97-106, 2007.

Critzer F.J., Kelly-Winterberg K., South S.L., Golden D.A.: Atmospheric plasma inactivation of foodborne pathogens on fresh produce surfaces. - J. Food Prot. 70: 2290-2296, 2007.

Daley P.F., Raschke K., Ball J.T., Berry J.A.: Topography of photosynthetic activity of leaves obtained from video images of chlorophyll fluorescence. - Plant Physiol. 90: 1233-1238, 1989.

DeEll J.R., Toinvonen P.M.A.: Use of chlorophyll fluorescence in postharvest quality assessments of fruits and vegetables. -
In: DeEll J.R., Toivonen P.M.A. (ed.): Practical Applications of Chlorophyll Fluorescence in Plant Biology. Pp. 203-242. Springer, Boston 2012.

DeEll J.R., van Kooten O., Prange R.K., Murr D.P.: Application of chlorophyll fluorescence techniques in postharvest physiology. - Hortic. Rev. 23: 69-107, 1999.

Demmig-Adams B., Adams III W.W., Barker D.H. et al.: Using chlorophyll fluorescence to assess the fraction of absorbed light allocated to thermal dissipation of excess excitation. Physiol. Plantarum 98: 253-264, 1996.

Deng L.-Z., Mujumdar A.S., Pan Z. et al.: Emerging chemical and physical disinfection technologies of fruits and vegetables: a comprehensive review. - Crit. Rev. Food Sci. Nutr. 60: 2481-2508, 2020.

Deng X.T., Shi J.J., Shama G., Kong M.G: Effects of microbial loading and sporulation temperature on atmospheric plasma inactivation of Bacillus subtilis spores. - Appl. Phys. Lett. 87: 153901, 2005.

Dong Z., Men Y., Li Z. et al.: Chlorophyll fluorescence imaging as a tool for analyzing the effects of chilling injury on tomato seedlings. - Sci. Hortic.-Amsterdam 246: 490-497, 2019.

Donis-González I.R., Guyer D.E., Fulbright D.W., Pease A.: Postharvest noninvasive assessment of fresh chestnut (Castanea spp.) internal decay using computer tomography images. - Postharvest Biol. Tec. 94: 14-25, 2014.

Ehlbeck J., Schnabel U., Andrasch M. et al.: Plasma treatment of food. - Contrib. Plasm. Phys. 55: 753-757, 2015.

Erkan M., Yıldırım I.: Postharvest quality and safety of fresh-cut vegetables. - In: Yildiz F., Wiley R. (ed.): Minimally Processed Refrigerated Fruits and Vegetables. Food Engineering Series. Pp. 271-326. Springer, Boston 2017.

Ferrante A., Incrocci L., Maggini R. et al.: Colour changes of fresh-cut leafy vegetables during storage. - J. Food Agric. Environ. 4: 40-44, 2004.

Ferrante A., Incrocci L., Serra G.: Quality changes during storage of fresh-cut or intact Swiss chard leafy vegetables. - J. Food Agric. Environ. 6: 60-62, 2008.

Forstreuter M., Schröder R., Herppich W.B.: Chlorophyllfluoreszenzbildanalyse zur raschen Indikation des Befalls von Laub- und Nadelbäumen durch herbivore Insekten. [Chlorophyll fluorescence imaging for rapid indication of infection of broad-leaved and coniferous trees by herbivorous insects.] - Bornim. Agrartech. Ber. 56: 26-33, 2006. [In German]

Fröhling A., Baier M., Ehlbeck J. et al:: Atmospheric pressure plasma treatment of Listeria innocua and Escherichia coli at polysaccharide surfaces: Inactivation kinetics and flow cytometric characterization. - Innov. Food Sci. Emerg. Technol. 13: 142-150, 2012.

Gergoff Grozeff G.E., Chaves A.R., Bartoli C.G.: Low irradiance pulses improve postharvest quality of spinach leaves (Spinacia oleraceae L. cv Bison). - Postharvest Biol. Tec. 77: 35-42, 2013.

Geyer M., Herppich W.B., Linke M.: Nicht-destruktive Verfahren zur Bestimmung des Wasserzustandes als Ausdruck der Frische von Gemüse. [Nondestructive methods for water status analyses, an indicator of produce freshness.] In: Proceedings 34. Vortragstagung 'Zerstörungsfreie Qualitätsanalyse'. Pp. 131-142. Deutsche Gesellschaft für Qualitätsforschung (Pflanzliche Nahrungsmittel), Kiel 1999.

Glowacz M., Mogren L.M., Reade J.P.H. et al.: Can hot water treatments enhance or maintain postharvest quality of spinach leaves? - Postharvest Biol. Tec. 81: 23-28, 2013.

Gorbe E., Calatayud A.: Applications of chlorophyll fluorescence imaging technique in horticultural research: A review. Sci. Hortic.-Amsterdam 138: 24-35, 2012. 
Grzegorzewski F., Rohn S., Kroh L.W. et al.: Surface morphology and chemical composition of lamb's lettuce (Valerianella locusta) after exposure to a low-pressure oxygen plasma. Food Chem. 122: 1145-1152, 2010.

Hägele F., Baur S., Menegat A. et al.: Chlorophyll fluorescence imaging for monitoring the effects of minimal processing and warm water treatments on physiological properties and quality attributes of fresh-cut salads. - Food Bioproc. Tech. 9: 650-663, 2016.

Haltia T., Freire E.: Forces and factors that contribute to the structural stability of membrane bound proteins. BBA-Bioenergetics 1228: 1-27, 1995.

Hasperué J.H., Rodoni L.M., Guardianelli L.M. et al.: Use of LED light for Brussels sprouts postharvest conservation. Sci. Hortic.-Amsterdam 213: 281-286, 2016.

Havaux M.: Stress tolerance of photosystem II in vivo: antagonistic effects of water, heat, and photoinhibition stresses. - Plant Physiol. 100: 424-432, 1992.

Hengari S., Theron K.I., Midgley S.J.E., Steyn W.J.: Differential dependence of apple (Malus domestica Borkh.) cultivars on the xanthophyll cycle for photoprotection. - S. Afr. J. Plant Soil 33: 69-76, 2016.

Henriques F.S.: Leaf chlorophyll fluorescence: Background and fundamentals for plant biologists. - Bot. Rev. 75: 249-270, 2009.

Herppich W.B.: Interactive effects of light and drought stress on photosynthetic activity and photoinhibition under (sub-) tropical conditions. - Acta Hortic. 531: 135-142, 2000.

Herppich W.B.: Hat Licht Einfluss auf die Qualität von frischem, verpackten Rucola und Feldsalat? [Does light affect the quality of fresh packed rucola and lamb's lettuce?] - In: Proceedings 5. Frische-Logistik-Tagung, Convenience und Fertiggerichte, logistische Anforderungen und Praktiken, 2003.

Herppich W.B., Foerster J., Zeymer J. et al:: Chlorophyll fluorescence imaging for non-destructively monitoring of changes in fresh and fresh-cut produce. - In: Nunes C. (ed.): Proceedings of the International Conference "Environmentally Friendly and Safe Technologies for Quality of Fruits and Vegetables”, Faro, Portugal, 14.-16. 1. 2009. Pp. 45-51, 2012.

Herppich W.B., Maggioni M., Huyskens-Keil S. et al.: Optimization of short-term hot-water treatment of apples for fruit salad production by non-invasive chlorophyllfluorescence imaging. - Foods 9: 820, 2020.

Herppich W.B., Zude M.: Chlorophyll fluorescence imaging analysis and fluorescence spectra analysis. Possible horticultural and agricultural applications. - Landtechnik 57: E98-E99, 2002.

Hertwig Ch., Reineke K., Ehlbeck J. et al.: Impact of remote plasma treatment on natural microbial load and quality parameters of selected herbs and spices. - J. Food Eng. 167: 12-17, 2015a.

Hertwig Ch., Reineke K., Ehlbeck J. et al.: Decontamination of whole black pepper using different cold atmospheric pressure plasma applications. - Food Control 55: 221-229, 2015 b.

Hüve K., Bichele I., Rasulov B., Niinemets Ü.: When it is too hot for photosynthesis: heat-induced instability of photosynthesis in relation to respiratory burst, cell permeability changes and $\mathrm{H}_{2} \mathrm{O}_{2}$ formation. - Plant Cell Environ. 34: 113-126, 2011.

Indrawati I., Ludikhuyze L.R., van Loey A.M., Hendrickx M.E. Lipoxygenase inactivation in green beans (Phaseolus vulgaris L.) due to high pressure treatment at subzero and elevated temperatures. - J. Agr. Food Chem. 48: 1850-1859, 2000.

Kabelitz T., Hassenberg K.: Control of apple surface microflora for fresh-cut produce by post-harvest hot-water treatment. LWT 98: 492-499, 2018.

Kabelitz T., Schmidt B., Herppich W.B., Hassenberg K.: Effects of hot water dipping on apple heat transfer and post-harvest fruit quality. - LWT 108: 416-420, 2019.

Kader A.A.: Respiration and gas exchange of vegetables. In: Weichmann J. (ed.): Postharvest Physiology of Vegetables. Pp. 25-43. Marcel Dekker, New York 1987.

Kautsky H., Hirsch A.: Neue Versuche zur Kohlensäureassimilation. [New experiments for the assimilation of $\mathrm{CO}_{2}$.] - Naturwissenschaften 19: 964, 1931. [In German]

Klughammer C., Schreiber U.: Complementary PS II quantum yields calculated from simple fluorescence parameters measured by PAM fluorometry and the saturation pulse method. - PAM Appl. Notes 1: 27-35, 2008.

Knorr D., Heinz V., Buckow R.: High pressure application for food biopolymers. - BBA-Proteins Proteom. 1764: 619-631, 2006.

Kong D., Zhao W., Ma Y. et al.: Effects of light-emitting diode illumination on the quality of fresh-cut cherry tomatoes during refrigerated storage. - Int. J. Food Sci. Technol. 56: 2041-2052, 2021

Kong M.G., Kroesen G., Morfill G. et al:: Plasma medicine: an introductory review. - New J. Phys. 11: 115012, 2009.

Koseki S., Isobe S.: Effect of ozonated water treatment on microbial control and on browning of iceberg lettuce (Lactuca sativa L.). - J. Food Prot. 69: 154-160, 2006.

Kosson R.: Chlorophyll fluorescence and chilling injury of green pepper as affected by storage conditions. - Acta Hortic. 628: 379-385, 2003.

Krause G.H., Galle A., Gademann R., Winter K.: Capacity of protection against ultraviolet radiation in sun and shade leaves of tropical forest plants. - Funct. Plant Biol. 30: 533-542, 2003.

Krause G.H., Weis E.: Chlorophyll fluorescence and photosynthesis: the basics. - Annu. Rev. Plant Phys. 42: 313-349, 1991.

Kuckenberg J., Tartachnyk I., Noga G.: Evaluation of fluorescence and remission techniques for monitoring changes in peel chlorophyll and internal fruit characteristics in sunlit and shaded sides of apple fruit during shelf-life. - Postharvest Biol. Tec. 48: 231-241, 2008.

Kurenda A., Zdunek A., Schlüter O., Herppich W.B.: VIS NIR spectroscopy, chlorophyll fluorescence, biospeckle and backscattering to evaluate changes in apples subjected to hydrostatic pressures. - Postharvest Biol. Tec. 96: 88-98, 2014.

Lazár D.: The polyphasic chlorophyll $a$ fluorescence rise measured under high intensity of exciting light. - Funct. Plant Biol. 33: 9-30, 2006.

Lichtenthaler H.K.: In vivo chlorophyll fluorescence as a tool for stress detection in plants. - In: Lichtenthaler H.K. (ed.): Applications of Chlorophyll Fluorescence in Photosynthesis Research, Stress Physiology, Hydrobiology and Remote Sensing. Pp. 129-142. Springer, Dordrecht 1988.

Lichtenthaler H.K.: Multi-colour fluorescence imaging of photosynthetic activity and plant stress. - Photosynthetica 59: 364-380, 2021.

Lichtenthaler H.K., Burgstahler R., Buschmann C. et al.: Effect of high light and high light stress on composition, function and structure of the photosynthetic apparatus. - In: Marcelle R., Clijsters H., van Poucke M. (ed.): Effects of Stress on Photosynthesis. Advances in Agricultural Biotechnology. Vol. 3. Pp. 353-370. Springer, Dordrecht 1983.

Lim C.S., Kang S.M., Cho J.L. et al.: Bell pepper (Capsicum annuиm L.) fruits are susceptible to chilling injury at the breaker stage of ripeness. - HortScience 42: 1659-1664, 2007.

Linke M., Herppich W.B., Geyer M.: Green peduncles may indicate postharvest freshness of sweet cherries. - Postharvest 
Biol. Tec. 58: 135-141, 2010.

$\mathrm{Lu}$ Y., Lu R.: Enhancing chlorophyll fluorescence imaging under structured illumination with automatic vignetting correction for detection of chilling injury in cucumbers. - Comput. Electron. Agr. 168: 105145, 2020.

Lukatkin A.S., Brazaityte A., Bobinas C., Duchovskis P.: Chilling injury in chilling-sensitive plants: a review. - Žemdirbyste 99: 111-124, 2012.

Lurie S.: Postharvest heat treatments. - Postharvest Biol. Tec. 14: 257-269, 1998

Maheswari M., Joshi G.K., Saha R. et al.: Transverse relaxation time of leaf water protons and membrane injury in wheat (Triticum aestivum L.) in response to high temperatures. Ann. Bot.-London 84: 741-745, 1999.

Marigheto N., Vial A., Wright K., Hills B.: A combined NMR and microstructural study of the effect of high-pressure processing on strawberries. - Appl. Magn. Reson. 26: 521-531, 2004.

Matyssek R., Herppich W.B.: Chlorophyllfluoreszenzanalyse. [Chlorophyll fluorescence analysis.] - In: Experimentelle Pflanzenökologie. Springer Reference Naturwissenschaften. Pp. 1-55. Springer Spektrum, Berlin-Heidelberg 2018. [In German]

Matyssek R., Herppich W.B.: Experimentelle Pflanzenökologie: Grundlagen und Anwendungen. [Experimental Plant Ecology: Basics and Applications.] Springer Reference Naturwissenschaften. Pp. 551. Springer Spektrum, BerlinHeidelberg 2020. [In German]

Maxwell K., Johnson G.N.: Chlorophyll fluorescence a practical guide. - J. Exp. Bot. 51: 659-668, 2000.

Mendis D.A., Rosenberg M., Azam F.: A note on the possible electrostatic disruption of bacteria. - IEEE Trans. Plasma Sci. 28: 1304-1306, 2000.

Meyerhoff O., Pfündel E.: Photosynthesis in ripe strawberries (Fragaria $\times$ ananassa) recording by a MAXI IMAGINGPAM. - PAM Appl. Notes 1: 19-20, 2008.

Nassarawa S.S., Abdelshafy A.M., Xu Y. et al.: Effect of lightemitting diodes (LEDs) on the quality of fruits and vegetables during postharvest period: a review. - Food Bioproc. Tech. 14: 388-414, 2021.

Nauš J., Dvořák L., Kuropatwa R., Mašláň M.: Transition in the thylakoid membranes of barley leaves studied by chlorophyll fluorescence temperature curve. - Photosynthetica 27: 563$570,1992$.

Nedbal L., Soukupová J., Kaftan D. et al.: Kinetic imaging of chlorophyll fluorescence using modulated light. - Photosynth. Res. 66: 3-12, 2000b.

Nedbal L., Soukupová J., Whitmarsh J., Trtílek M.: Postharvest imaging of chlorophyll fluorescence from lemons can be used to predict fruit quality. - Photosynthetica 38: 571-579, 2000c.

Nedbal L., Trtílek M., Herppich W.B.: Methods and equipment for fluorescence imaging on plant material. - Bornim. Agrartech. Ber. 25: 127-135, 2000a.

Nicolaï B.M., Beullens K., Bobelyn E. et al.: Nondestructive measurement of fruit and vegetable quality by means of NIR spectroscopy: A review. - Postharvest Biol. Tec. 46: 99-118, 2007.

Noh H.K., Lu R.: Hyperspectral laser-induced fluorescence imaging for assessing apple fruit quality. - Postharvest Biol. Tec. 43: 193-201, 2007.

Omasa K., Shimazaki K., Aiga I. et al.: Image analysis of chlorophyll fluorescence transients for diagnosing the photosynthetic system of attached leaves. - Plant Physiol. 84: 748-752, 1987.

Oseko J., East A., Heyes J.: Can changes in chlorophyll fluorescence be used to determine chilling injury of cold stored feijoa? - Acta Hortic. 1275: 125-132, 2020.
Oxborough K.: Imaging of chlorophyll $a$ fluorescence: theoretical and practical aspects of an emerging technique for the monitoring of photosynthetic performance. - J. Exp. Bot. 55: 1195-1205, 2004.

Parkin K.L., Marangoni A., Jackman R.L. et al.: Chilling injury. A review of possible mechanisms. - J. Food. Biochem. 13: 127-153, 1989.

Pastenses C., Horton P.: Resistance of photosynthesis to high temperature in two bean varieties (Phaseolus vulgaris L.). Photosynth. Res. 62: 197-203, 1999.

Pfündel E.: Estimating the contribution of photosystem I to total leaf chlorophyll fluorescence. - Photosynth. Res. 56: 185195, 1998.

Pieczywek P., Cybulska J., Szymańska-Chargot M. et al.: Early detection of fungal infection of stored apple fruit with optical sensors - Comparison of biospeckle, hyperspectral imaging and chlorophyll fluorescence. - Food Control 85: 327-338, 2018.

Porcar-Castell A., Tyystjärvi E., Atherton J. et al.: Linking chlorophyll $a$ fluorescence to photosynthesis for remote sensing applications: mechanisms and challenges. - J. Exp. Bot. 65: 4065-4095, 2014.

Prange R.K., Lidster P.D.: Controlled atmosphere and lighting effects on storage of winter cabbage. - Can. J. Plant Sci. 71: 263-268, 1991.

Purvis A.C.: Diphenylamine reduces chilling injury of green bell pepper fruit. - Postharvest Biol. Tec. 25: 41-48, 2002.

Rico D., Martín-Diana A.B., Barat J.M., Barry-Ryan C.: Extending and measuring the quality of fresh-cut fruit and vegetables: a review. - Trends Food Sci. Tech. 18: 373-386, 2007.

RKI: Final presentation and evaluation of epidemiological findings in the EHEC O104:H4 outbreak in Germany, 2011. Robert Koch Institute (RKI), Berlin 2011.

Rux G., Gelewsky R., Schlüter O., Herppich W.B.: High hydrostatic pressure effects on membrane-related quality parameters of fresh radish tubers. - Postharvest Biol. Tec. 151: $1-9,2019$.

Rux G., Gelewsky R., Schlüter O., Herppich W.B.: High hydrostatic pressure treatment effects on selected tissue properties of fresh horticultural products. - Innov. Food Sci. Emerg. Technol. 61: 102326, 2020.

Rux G., Schlüter O., Geyer M. et al.: Characterization of high hydrostatic pressure effects on fresh produce cell turgor using pressure probe analyses. - Postharvest Biol. Tec. 132: 188194, 2017.

Sánchez-Moreiras A., Graña E., Reigosa M.J., Araniti F.: Imaging of chlorophyll $a$ fluorescence in natural compound-induced stress detection. - Front. Plant Sci. 11: 583590, 2020.

Sandmann M., Grosch R., Graefe J.: The use of features from fluorescence, thermography, and NDVI imaging to detect biotic stress in lettuce. - Plant Disease 102: 1101-1107, 2018.

Schlüter O., Ehlbeck J., Hertel Ch. et al.: Opinion on the use of plasma processes for treatment of foods. - Mol. Nutr. Food Res. 57: 920-927, 2013.

Schlüter O., Foerster J., Fröhling A. et al:: Stress response of physiological active food products on high hydrostatic pressures up to $250 \mathrm{MPa}$ - American Society of Agricultural and Biological Engineers Paper Number 084125, St. Joseph, USA, 2008.

Schlüter O., Foerster J., Geyer M. et al.: Characterization of high hydrostatic pressure effects on fresh produce using chlorophyll fluorescence image analysis. - Food Bioproc. Tech. 2: 291-299, 2009.

Schnabel U., Niquet R., Krohmann U. et al.: Decontamination of microbiologically contaminated specimen by direct and 
indirect plasma treatment. - Plasma Process. Polym. 9: 569$575,2012$.

Scholes J.D., Rolfe S.A.: Photosynthesis in localised regions of oat leaves infected with crown rust (Puccinia coronata): Quantitative imaging of chlorophyll fluorescence. - Planta 199: 573-582, 1996.

Schreiber U., Schliwa U., Bilger W.: Continuous recording of photochemical and non-photochemical quenching with a new type of modulation fluorometer. - Photosynth. Res. 10: 51-62, 1986.

Sevillano L., Sanchez-Ballesta M.T., Romojaro F., Flores F.B.: Physiological, hormonal and molecular mechanisms regulating chilling injury in horticultural species. Postharvest technologies applied to reduce its impact. - J. Sci. Food Agr. 89: 555-573, 2009.

Shao X.F., Tu K., Zhao Y.Z. et al.: Effects of prestorage heat treatment on fruit ripening and decay development in different apple cultivars. - J. Hortic. Sci. Biotech. 82: 297-303, 2007.

Simko I., Jimenez-Berni J.A., Furbank R.T.: Detection of decay in fresh-cut lettuce using hyperspectral imaging and chlorophyll fluorescence imaging. - Postharvest Biol. Tec. 106: 44-52, 2015.

Strasser R.J., Srivastava A., Govindjee: Polyphasic chlorophyll $a$ fluorescence transient in plants and cyanobacteria. Photochem. Photobiol. 61: 32-42, 1995.

Szwejda-Grzybowska J.I., Wrzodak A., Grzegorzewska M.: Influence of tap and hot water treatment before short-term storage on biologically active compounds and sensory quality of wild rocket leaves (Diplotaxis tenuifolia L.). - J. Hortic. Res. 27: 113-120, 2019.

Tijskens L.M.M., Otma E.C., van Kooten O.: Photosystem II quantum yield as a measure of radical scavengers in chilling injury in cucumber fruits and bell peppers. A static, dynamic and statistical model. - Planta 194: 478-486, 1994.

Trejo Araya X., Hendrickx M., Verlinden B.E. et al.: Understanding texture changes of high pressure processed fresh carrots: a microstructural and biochemical approach. J. Food Eng. 80: 873-884, 2007.

Trierweiler B., Schirmer H., Tauscher B.: Hot water treatment to control Gloeosporium disease on apples during long-term storage. - J. Appl. Bot. 77: 156-159, 2003.

Vargas-Ortiz M.A., De la Cruz-Medina J., Espinosa de los Monteros J.J.: Effect of high hydrostatic pressure on the physiology of Manila mango. - Plant Food. Hum. Nutr. 68: 137-144, 2013. von Willert D.J., Matyssek R., Herppich W.B.: Experimentelle Pflanzenökologie: Grundlagen und Anwendungen. [Experi= mental Plant Ecology: Basics and Applications.] Pp. 344. Georg Thieme Verlag, Stuttgart 1995. [In German]

Weber J.F., Kunz Ch., Peteinatos G.G. et al.: Utilization of chlorophyll fluorescence imaging technology to detect plant injury by herbicides in sugar beet and soybean. - Weed Technol. 31: 523-535, 2017.

Wei C.I., Cook D.L., Kirk J.R.: Use of chlorine compounds in the food industry. - Food Technol. 39: 107-115, 1985.

Weltmann K.-D., Brandenburg R., von Woedtke T. et al.: Antimicrobial treatment of heat sensitive products by miniaturized atmospheric pressure plasma jets (APPJs). J. Phys. D. Appl. Phys. 41: 194008, 2008.

Yu Y., Tia S.M., Ruan K.C., Xu C.H.: The release of extrinsic polypeptides and manganese cluster from photosystem 2 membranes under high hydrostatic pressure. - Photosynthetica 39: 115-117, 2001.

Žabka M., Drastichová K., Jegorov A. et al.: Direct evidence of plant-pathogenic activity of fungal metabolites of Trichothecium roseum on apple. - Mycopathologia 162: 6568, 2006.

Zdunek A., Herppich W.B.: Relation of biospeckle activity with chlorophyll content in apples. - Postharvest Biol. Tec. 64: 58-63, 2012.

Zhan L., Li Y., Hu J. et al.: Browning inhibition and quality preservation of fresh-cut romaine lettuce exposed to high intensity light. - Innov. Food Sci. Emerg. Technol. 14: 70-76, 2012.

Zhang B., Huang W., Li J. et al.: Principles, developments and applications of computer vision for external quality inspection of fruits and vegetables: A review. - Food Res. Int. 62: 326$343,2014$.

Zsom T., Strohmeyer E., Nguyen L.P.L. et al.: Chilling injury investigation by non-destructive measuring methods during banana cold storage. - Prog. Agric. Eng. Sci. 14: 147-158, 2018.

Zsom T., Zsom-Muha V., Baranyai L. et al:: Non-destructive determination of post-harvest ripening of Capsicum annuum 'Kárpia'. - Acta Hortic. 858: 407-412, 2010.

Zsom T., Zsom-Muha V., Nguyen L.P.L et al.: Nondestructive detection of low temperature induced stress on postharvest quality of kápia type sweet pepper. - Prog. Agric. Eng. Sci. 16: 173-186, 2020.

(C) The authors. This is an open access article distributed under the terms of the Creative Commons BY-NC-ND Licence. 